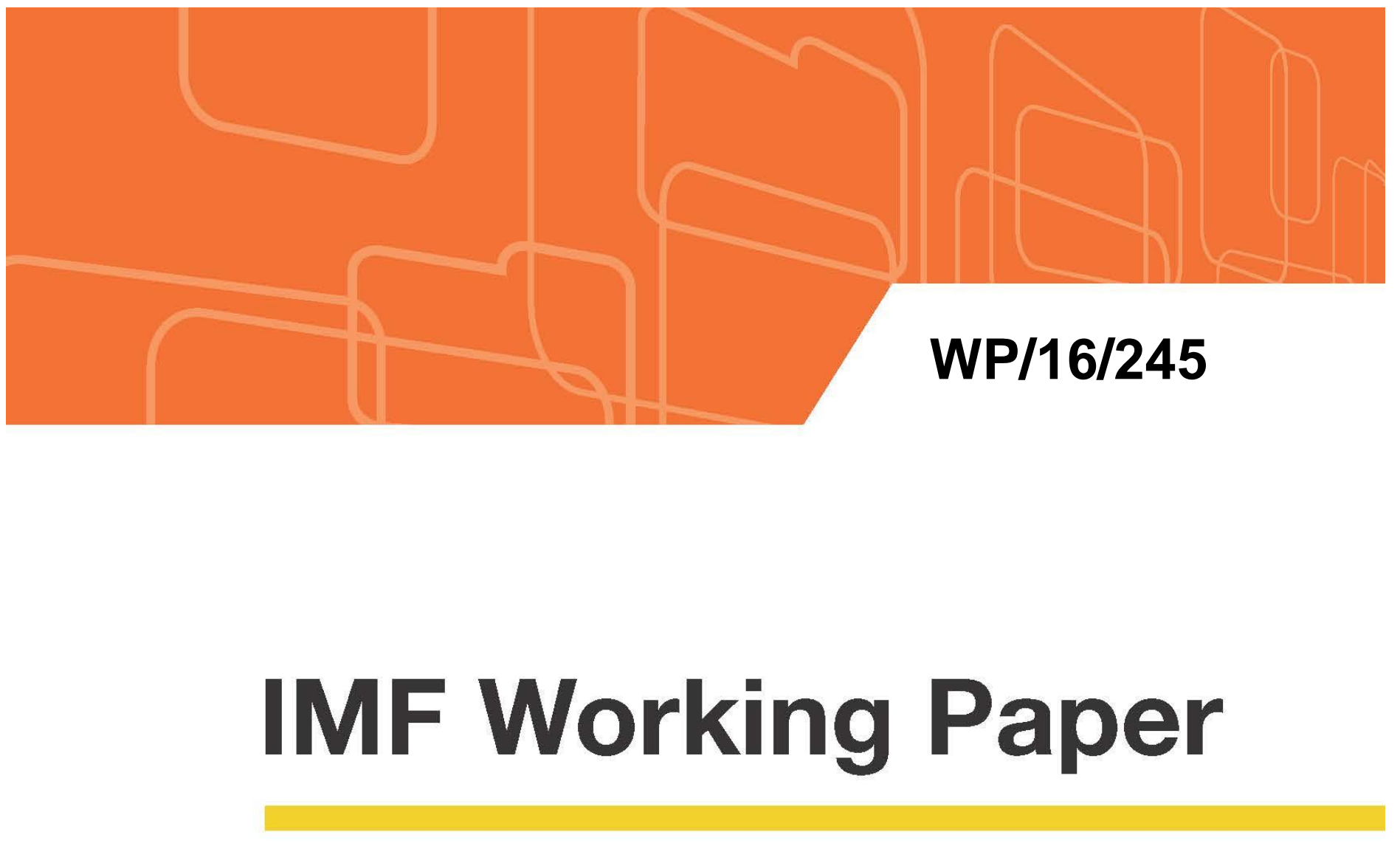

\title{
The Effects of Monetary Policy Shocks on Inequality
}

By Davide Furceri, Prakash Loungani, and Aleksandra Zdzienicka

IMF Working Papers describe research in progress by the author(s) and are published to elicit comments and to encourage debate. The views expressed in IMF Working Papers are those of the author(s) and do not necessarily represent the views of the IMF, its Executive Board, or IMF management. 


\title{
IMF Working Paper
}

\author{
Research Department
}

\section{The Effects of Monetary Policy Shocks on Inequality}

Prepared by Davide Furceri (IMF), Prakash Loungani (IMF), and Aleksandra Zdzienicka (IMF)

Authorized for distribution by Prakash Loungani

December 2016

\section{IMF Working Papers describe research in progress by the author(s) and are published to} elicit comments and to encourage debate. The views expressed in IMF Working Papers are those of the author(s) and do not necessarily represent the views of the IMF, its Executive Board, or IMF management.

\begin{abstract}
This paper provides new evidence of the effect of monetary policy shocks on income inequality. Using a measure of unanticipated changes in policy rates for a panel of 32 advanced and emerging market countries over the period 1990-2013, the paper finds that contractionary (expansionary) monetary actions increase (reduce) income inequality. The effect, however, varies over time, depending on the type of the shocks (tightening versus expansionary monetary policy) and the state of the business cycle, and across countries depending on the share of labor income and redistribution policies. In particular, we find that the effect is larger for positive monetary policy shocks, especially during expansions. Looking across countries, we find that the effect is larger in countries with higher labor share of income and smaller redistribution policies. Finally, while an unexpected increase in policy rates increases inequality, changes in policy rates driven by an increase in growth are associated with lower inequality.
\end{abstract}

JEL Classification Numbers: E62, E64, D63

Keywords: monetary policy; monetary policy shocks; income inequality. Author's E-Mail Address: dfurceri@imf.org; ploungani@imf.org; azdzienicka@imf.org 


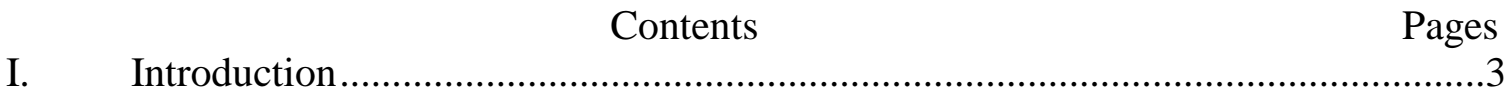

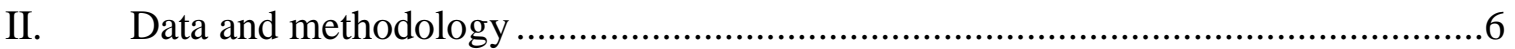

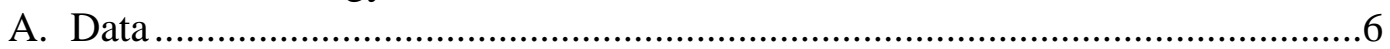

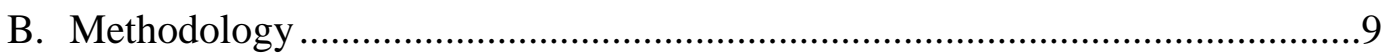

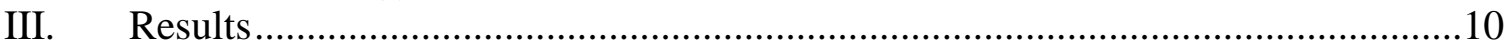

A. Baseline Results and Robustness Checks ...................................................10

B. Different Measures of Inequality ................................................................

C. Type of Monetary Policy Shocks......................................................................13

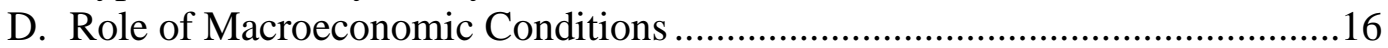

IV. Wealth Inequality ............................................................................19

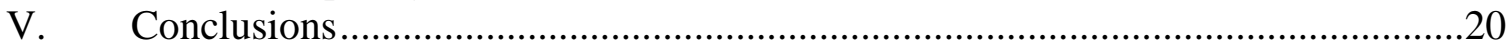

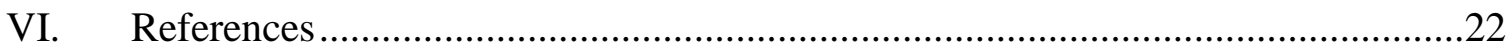

\section{FIGURES}

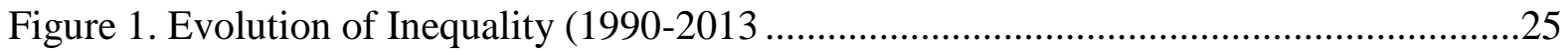

Figure 2 Exogenous Monetary Policy Shocks for the United States .......................................26

Figure 3. The effect of monetary policy on output, unemployment and inflation...................27

Figure 4. The effect of monetary policy shocks on income inequality (Net Gini), 1990-

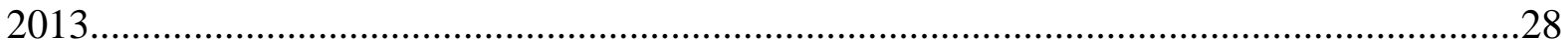

Figure 5. The effect of monetary policy shocks on income inequality, robustness checks .....29

Figure 6. The effect of monetary policy on top income shares .............................................31

Figure 7. The effect of monetary policy shocks on the share of wage income in GDP ..........32

Figure 8 . The effect of monetary policy on income inequality, positive vs. negative shocks.33 Figure 9 . The effect of monetary policy on income inequality, exogenous vs. growth driven

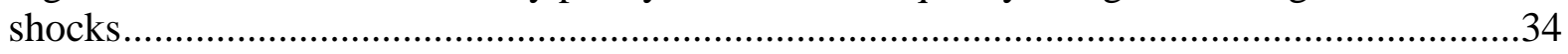

Figure 10. The effect of monetary policy on income inequality, the role of business cycle ...35

Figure 11. The effect of monetary policy on income inequality, the role of labor earnings ...36

Figure 12. The effect of monetary policy on income inequality, the role of redistribution......37

Figure 13. The effects of monetary policy shocks on equity and house price index ................38

\section{TABLES}

Table1. Descriptive statistics

Table 2. The effect of monetary policy shocks on income inequality (Net Gini), 1990-201340

\section{ANNEXES}

Table A1. List of countries in the sample 


\section{INTRODUCTION}

Growing inequality, in particular in advanced economies, has attracted much attention among policymakers (e.g., Yellen 2014; Bernanke 2015, Draghi 2016) and in the press and academia. An extensive literature has suggested many causes of inequality, including technological progress (Bound and Johnson 1992; Acemoglu 2002), demographics (Karahan and Ozkan 2013), globalization (Feenstra and Hanson 2008, Furceri and Loungani 2015), and structure of the labor market (Jaumotte and Osorio-Buitron 2015). Increasingly, however, attention has been focused on the role of conventional and unconventional monetary policy in affecting inequality over the cycle. In particular, concerns have risen that the current accommodative monetary policy stance in many advanced economies may negatively affect income and wealth distribution (Acemoglu and Johnson 2012; Stiglitz 2015). This view, however, is at odds with others that suggest that expansionary monetary policy by boosting employment can reduce inequality. Draghi (2016), for example, has recently argued that:

"Over the medium-term, it is unambiguous that monetary policy has positive distributional effects through macroeconomic channels. Most importantly, it reduces unemployment, which benefits poorer households the most. And a faster return to full employment should, in turn, contribute to lower future inequality, since we know that if unemployment lasts too long it can lead to permanent income losses through labour market scarring."

In theory, the effect of monetary policy on inequality is ambiguous as the quantitative importance of different transmission channels can result in its increase or decrease. For instance, expansionary monetary policy can increase inequality by boosting asset prices and/or inflation.

In the first case, the effect depends on the composition of household income and the impact of monetary policy on different asset prices. Top-income households receiving higher shares of financial income than low-income households tend to benefit more. In the second case, expansionary monetary policy increases income inequality through higher inflation as lowincome households relying primarily on labor earnings hold more liquid assets than high-income 
ones. At the same time, there are other transmission channels that would predict that

expansionary monetary policy can reduce inequality. First, expansionary monetary policy can

reduce inequality through savings retribution as an unexpected decrease in policy rates will

benefit borrowers_-generally those less wealthy — and hurt savers (Doepke and Schneider 2006).

Second, since labor earnings at the bottom of the distribution are most affected by changes in

economic activity (Heathcote and others 2010), a decrease increase in monetary policy rates

would lead to a decline in inequality.

From an empirical point of view, a growing literature has usually found that the effects of monetary policy on income inequality have been relatively modest—even sometimes of different signs - and varying across countries (Coibion and others 2012; Bivens 2015; Adam and Tzamourani 2015; Guerello 2016, O’Farrell and others 2016). ${ }^{1}$ This paper contributes to this literature by assessing how monetary policy affects income inequality for a panel of 32 advanced economies and emerging market countries over the period of 1990-2013. In particular, our contribution is threefold:

\footnotetext{
${ }^{1}$ Coibion and others (2012) find that in the United States monetary policy tightening increases inequality, with highearning households (the $90^{\text {th }}$ percentile) earning about 4 percent more labor income after contractionary shocks while the labor income for low-earning household (the $10^{\text {th }}$ percentile) declining by 4 percent in the long run. Guerello (2016) find similar results using survey measure of inequality for the Euro zone countries. O'Farrell and others (2016) conclude that the effects of monetary policy on inequality through financial channels tend to be small and vary significantly for 8 OECD countries: a percentage point lower policy rates increases the net Gini coefficient by up to 0.02 percent after 3 years. Huber and Stephens (2014) find that a 100 basis point reduction in policy rates reduces the Gini coefficient by 0.4 percent. Bivens (2015) argues that expansionary monetary policy could reduce inequality if the economy is close to full employment, but that the relative distributional effects of recent Fed policy actions are small. Saiki and Frost (2014) find evidence that expansionary unconventional monetary policy increases inequality in Japan. Casiraghi and others (2016) find that recent monetary policy measures have a negligible overall effect on inequality in Italy. Also, Adam and Tzamourani (2015) looking at asset prices inflation —as that triggered by recent unconventional monetary policy measures - point to conflicting results. For instance, equity price increase benefits the top 5percent of the net wealth distribution while housing prices inflation reduces inequality.
} 
(i) identifying the causal effect of monetary policy shocks on inequality, borrowing from the recent literature on fiscal policy (Auerbach and Gorodnichenko 2013; Abiad and others 2015) and construct unexpected changes in policy rates that are orthogonal to innovations in economic activity;

(ii) examining the impact of monetary policy on inequality for a large sample of advanced and emerging market economies;

(iii) assessing whether the effects of monetary policy shocks vary over time, depending on the type of the shocks (tightening versus expansionary monetary policy) and the state of the business cycle, and across countries depending on the initial level of inequality and the share of labor income to total income.

We find that an unexpected increase of 100 basis points in the policy rate increases inequality by about $1 \frac{1 / 4}{4}$ percent in the short term and by about $2 \frac{1 / 4}{4}$ percent in the medium term. The effect is also economically significant, given the high persistence and limited variation in the Gini coefficient, and is robust across different measures of inequality (top income shares and the share of wage income in GDP). In particular, the magnitude of the medium-term effect is approximately equivalent to 1 standard deviation of the change in the Gini coefficient (2.4 percent) in the sample. The effect, however, varies over time, depending on the type of the shocks (tightening versus expansionary monetary policy) and the state of the business cycle, and across countries depending on the share of labor income and redistribution policies. In particular, we find that the effect is larger for positive monetary policy shocks - especially during expansions. This asymmetry may suggest persistent effects of monetary policy shocks on inequality. Looking across countries, we find that the effect is larger in countries with higher labor share of income and more limited redistribution policies. 
We also find substantial differences between the effects of systematic and unexpected components of monetary policy. While an unexpected increase in policy rates increases inequality, an increase in policy rates driven by an increase in growth is associated with lower inequality. This contrast may help to explain the modest and highly uncertain impact of changes in monetary policy rates on inequality documented in the previous literature.

Finally, empirical evidence on the effect of monetary policy shocks on asset prices seems to suggest that expansionary monetary policy increases wealth inequality in the short term but reduces it in the medium term.

The rest of the paper is organized as follows. Section II discusses the data, the measures of monetary policy shocks and income inequality, and the methodology. Section III presents the results on income inequality. Sections IV provides some evidence on the implications of monetary policy on wealth inequality. Section V summarizes the main findings.

\section{DATA AND METHODOLOGY}

\section{A. Data}

\section{Measures of inequality}

Data on income inequality are taken from the Standardized World Income Inequality Database (SWIID 5.1). ${ }^{2}$ The SWIID includes measures of net (post-tax, post-transfers) and market (pre-tax, pre-transfers) income inequality (Gini indices) for 174 countries from 1960 to 2013. It incorporates data from several sources (United Nations University’s World Income Inequality Database, the OECD Income Distribution Database, World Bank, Eurostat, the Luxembourg Income Study) and standardizes it (see Solt 2016 for details on the methodology).

\footnotetext{
${ }^{2}$ See http://fsolt.org/swiid/ for more details.
} 
As a robustness check, we use data on top income shares from the World Top Incomes

Databases (WTID) and on the share of wage income in GDP from the OECD.

Gini coefficients are theoretically bounded between 0 (each reference unit receives an equal share of income) and 100 (a single reference unit receives all income). In our sample, they range from 18 to 54 for net measures and from 30 to 57 for gross measures, with higher levels of inequality typically recorded for developing countries (Table 1).

Figure 1 presents the evolution of net and market inequality measures for both advanced economies and emerging market countries over the period 1990-2013. In advanced economies, both measures of inequality have steadily increased throughout the sample, though there are significant cross-country differences in distribution. In contrast, in emerging market economies, inequality increased from the mid-90s to the mid-2000s but has recently declined.

\section{Monetary policy shocks}

While changes in monetary policy rates are not driven by inequality, economic conditions can influence — at least in the short term — both inequality and monetary policy actions. Therefore, estimating the causal effect of monetary policy on inequality requires using "exogenous" monetary policy shocks. We follow the approach developed by Auerbach and Gorodnichenko (2013) to identify fiscal policy shocks. In particular, we first compute the forecast error of the policy rates $\left(F E_{t}^{i}\right)$, defined as the difference between the actual policy rates $\left(S T_{t}^{i}\right)$ and the rate expected by analysts as of October of the same year $\left(C T_{t}^{i}\right)$ using forecasts from Consensus Economics: ${ }^{3}$

$F E_{i, t}^{i}=S T_{i, t}^{i}-C T_{i, t}^{i}$

\footnotetext{
${ }^{3}$ When data on policy rates are not available, we proxy this with short-term (typically 3 months) rates.
} 
We then regress for each country the forecast errors of the policy rates $\left(S T_{t}^{i}\right)$ on similarly computed forecast errors of inflation $\left(F E^{\text {inf }}\right)$ and output growth $\left(F E^{g}\right)$ :

$F E_{i, t}^{i}=\alpha+\beta F E_{i, t}^{i n f}+\gamma F E_{i, t}^{g}+\epsilon_{i, t}$

where the residual- $\epsilon_{i, t}$ - captures exogenous monetary policy shocks $(M P){ }^{4}$

This methodology overcomes two problems that may confound the causal estimation of the effect of monetary policy shocks on inequality. First, using forecast errors eliminates the problem of "policy foresight" (see Forni and Gambetti 2010; Leeper, Richter, and Walker 2012; Leeper, Walker, and Yang 2013; and Ben Zeev and Pappa 2014). Agents may receive news about changes in monetary policy in advance and may alter their consumption and investment behavior well before the changes in policy occur. An econometrician who uses just the information contained in the change in actual policy rate would be relying on a smaller information set than that used by economic agents, leading to inconsistent estimates of the effects of monetary policy shocks. ${ }^{5}$ In contrast, by using forecast errors in policy rates this methodology effectively aligns the economic agents' and the econometrician's information sets. Second, by purging news in growth and inflation from the forecast errors we significantly reduce the likelihood that the estimates capture the potentially endogenous response of monetary policy to the state of the economy.

To check the validity of the shocks constructed we perform two exercises. In the first, we compare the evolution of these shocks for the United States with those identified by Romer and Romer (2004). Panel A of Figure 2 shows that the two shocks series exhibit a very similar

\footnotetext{
${ }^{4}$ See Table 1 for descriptive statistics of these shocks and Appendix I for their density distribution.

${ }^{5}$ Leeper, Richter, and Walker (2012) demonstrate the potentially serious econometric problems that result from fiscal foresight, showing that when agents foresee changes in fiscal policy, the resulting time series have nonfundamental representation.
} 
pattern and are highly correlated (correlation about 0.8). In particular, the shocks we constructed match very well the large monetary policy contractions and expansions identified by Romer and Romer (2004) in the last 20 years.

As a second exercise, we check whether the effects of our shocks on key macroeconomic variables, such as output, unemployment, and inflation, are comparable with those reported in the literature, in particular by Romer and Romer (2004) for the United States. ${ }^{6}$ For this purpose, we estimate the response of these variables to monetary policy shocks using the local projection method proposed by Jorda (2005)—see next section for details—for an unbalanced panel of 32 economies from 1990 to $2013 .^{7}$ The results reported in Figure 3 shows that monetary policy shocks have statistically significant and somewhat persistent effects on output, unemployment, and inflation. Moreover, the estimated average effects in our sample, particularly for unemployment, are comparable and not statistically different from the one reported by Romer and Romer (2004). ${ }^{8}$

\section{B. Methodology}

To estimate the impact of monetary policy shocks on inequality in the short and medium term, we follow the method proposed by Jorda (2005), which consists of estimating impulse response

\footnotetext{
${ }^{6}$ While correctly assessing the impact of these shocks on variables that are available at monthly or quarterly frequency would require higher frequency shocks, the exercise is still useful to check the validity of these shocks and to understand the transmission channels through which they affect inequality.

${ }^{7}$ Given the limited time series, we cannot examine the effect of our US shocks on US macroeconomic series.

${ }^{8}$ See Coibion (2012) for a discussion on how big/small are the effects of monetary policy shocks and a range of plausible effects.
} 
functions (IRFs) directly from local projections. Specifically, for each future period $k$ the following equation is estimated on annual data:

$y_{i, t+k}-y_{i, t}=\alpha_{i}^{k}+\vartheta_{t}^{k}+\beta^{k} M P_{i, t}+\pi^{k} X_{i, t}+\varepsilon_{i, t}^{k}$

where $y$ is the (log of) net or market income inequality; $M P_{i, t}$ are exogenous monetary policy shocks; $a_{i}$ are country fixed effects included to control for unobserved cross-country heterogeneity of inequality and also to control for the fact that in some countries inequality is measured using income data while in other countries using consumption data ; $\vartheta_{t}$ are time fixed effects to control for global shocks; $X$ is a set of controls including lagged monetary policy shocks and lagged changes in inequality. ${ }^{9}$

Equation (3) is estimated for $\mathrm{k}=0, \ldots, 4-$ that is, up to five years after the shock. Impulseresponse functions are computed using the estimated coefficients $\beta^{k}$ and the confidence intervals using the estimated standard errors of these coefficients. The sample period—determined by the availability of the series of monetary policy shocks and inequality—is from 1990 to 2013 . The estimates for 32 advanced economies and emerging market countries (see Appendix I for a list of the countries) are based on clustered robust standard errors.

\section{RESULTS}

\section{A. Baseline Results and Robustness Checks}

\section{Baseline}

The results of estimating Equation 3 using the Gini coefficient for disposable income (net Gini) as the measure of inequality are presented in Figure 4 (see also Table 2). The figure shows the estimated effect of unanticipated monetary policy shocks and the associated confidence

\footnotetext{
${ }^{9}$ Results are robust to different lags.
} 
bands (dotted lines). The results show that monetary policy tightening leads to a long-lasting increase in income inequality. In particular, the estimates suggest that an unanticipated policy rate increase of 100 basis increases the Gini index by about $1 \frac{1 / 4}{4}$ in the very short term-1 year after the shock — and by about $2 \frac{1}{4}$ percent in the medium term -5 years after the shock. The effect eventually levels off, after seven years, at about $2 \frac{1 / 2}{2}$ percent.

The effect is also economically significant given the high persistence and limited variation in the Gini coefficient. In particular, the magnitude of the medium-term effect is approximately equivalent to 1 standard deviation of the change in the Gini coefficient (2.4 percent) in the sample—or to about 8 percentage points—and is larger than the sample average cumulative increase of the Gini coefficient over five consecutive years (about 2 percent). The effect is also slightly larger — even though not statistically different — than the one found by Coibion and others (2012) for the United States (about 3-5 percentage points- that is, about 1.11.5 percent).

\section{Robustness checks}

To check the robustness of the results, several alternative estimations are carried out. First, we re-estimate equation (3) using the gross Gini (market measure) as a measure of inequality to assess whether the results are driven by the effect of monetary policy on redistribution - that is, the difference between gross and net Gini. In particular, an increase in policy rates can affect negatively economic activity and therefore reduce budget resources for distribution, which would produce larger estimates on net inequality. The results presented in Panel A of Figure 5 suggest that the effects on gross inequality, albeit slightly smaller, are not statistically different from those obtained for net inequality. 
Second, we re-estimate equation (3) only for advanced economies to check whether the results are driven by relatively larger forecast errors in emerging market economies. The results obtained for this sample are quantitatively similar to and not statistically significantly different from those obtained for the full sample (Panel B, Figure 5).

Third, since policy rates in many advanced countries have approached their zero lower bounds and have not changed much in recent years, we re-estimate equation (3) only for the 1990-2007 sample. The results presented in Panel C of Figure 5 suggest that the effects of monetary policy shocks have been larger before 2008, with an unanticipated policy rate shock of 100 basis increases the Gini index by about $1 \frac{1 / 2}{2}$ percent in the very short term -1 year after the shock - and by about $2 \frac{3}{4}$ percent in the medium term -5 years after the shock. The fact that the effect is larger than the one based on the full sample is not surprising given the limited movements in policy rates in many advanced economies in recent years. That said, in this case too the effects are not statistically significantly different from those presented in the baseline.

Finally, we check whether the effect of monetary policy shocks on inequality could be biased because of endogeneity, as unobserved factors influencing inequality may also affect the magnitude of the monetary policy shocks. In particular, we re-estimate equation (3) including as additional controls: (i) dummies for recessions - proxied here as periods of negative growthwhich may directly affect inequality (Atkinson and Morelli 2011; Agnello and Sousa 2012) as well as the response of monetary policy to economic conditions, beyond the "normal" effect of growth news on policy rates forecast errors; (ii) change in the budget balance, since fiscal consolidation typically increases inequality (Ball and others 2013) and may affect the response of monetary policy to shocks as well as its impact on economic activity. The results of this exercise are reported in Panel D of Figure 5 and confirm the robustness of our results. 


\section{B. Different measures of inequality}

The Gini index is the most commonly used measured of inequality, mostly owing to its wider data availability compared to other measures. However, some of the observations in the SWIID database are obtained by model-based imputations and therefore subject to possibly large measurement errors (Solt, 2016). ${ }^{10}$ While this is less the case for the sample of economies considered in the analysis (which are mostly advanced ones), we check the validity of our results by re-estimating equation (3) using two different measures of inequality: (i) the top income share series (10, 5, and 1 percent) from the World Top Incomes Databases (WTID); (ii) the share of wage income in GDP from the OECD.

Starting with the first of these measures, the results presented in Figure 6 confirm that monetary policy tightening increases inequality. In particular, a 100 basis points monetary policy shock has a significant and persistent effect on all top income shares, with the effect being larger for the top 1 percent of population—about 0.8 percentage point four years after the shock.

Similarly, we find that an unexpected 100 basis points increase in the policy rates lead to a statistically significant and persistent decline in the share of wage income in GDP-about $1 / 2$ percentage point in the short term and about $1 \frac{1 / 2}{2}$ percentage points in the medium term (Figure 7).

\section{Type of monetary policy shocks}

\section{Positive versus negative monetary policy shocks}

Does the sign (positive versus negative) of the monetary policy shock matter for inequality? There is a growing consensus in the literature that the effects of positive monetary

\footnotetext{
10 The index is also criticized for being more sensitive to the income of the middle class and not capturing the exact distribution of income as identified by the Lorenz curve.
} 
policy shocks - that is, a contractionary monetary policy — on economic activity are larger than the effects of negative monetary policy shocks — an expansionary policy (see Barnichon and Mattes 2015, and references cited therein). This asymmetry in the monetary policy transmission can reflect, for instance, credit market imperfections when, with higher interest rates, less liquid firms cannot access external financing and cut investment and demand for credit (Bernanke and Blinder, 1988). Also, smaller less liquid banks might face funding shocks and cut the supply of credit (Kashyap and Stein, 2000). ${ }^{11}$ Given that an important transmission channel for the effect of monetary policy on inequality is through its impact on economic activity, it is likely to be the case that positive monetary policy shocks also have a larger effect on inequality than negative ones. To test this hypothesis, we re-estimate the following version of equation (3):

$y_{i, t+k}-y_{i, t}=\alpha_{i}^{k}+\vartheta_{t}^{k}+\beta_{+}^{k} D_{i, t} M P_{i, t}+\beta_{-}^{k}\left(1-D_{i, t}\right) M P_{i, t}+\pi^{k} X_{i, t}+\varepsilon_{i, t}^{k}$,

where $D$ is a dummy variable that takes value one for positive monetary policy shocks and zero otherwise.

The results show that the sign of monetary policy shocks does matter: while positive monetary policy shocks lead to a statistically significant increase in inequality in the medium term (about $4 \frac{1}{2}$ percent), the medium-term effect of negative monetary policy shocks is not statistically significantly different from zero (Figure 8).

\section{Exogenous versus growth-driven monetary policy shocks}

The results of the previous section have shown that innovations in policy rates that are orthogonal to innovations in output growth and inflation lead to a persistent increase in inequality. However, an interesting question at the current juncture is whether an increase in

\footnotetext{
${ }^{11}$ Florio (2004) and references therein.
} 
policy rates due to normalization in economic activity — such as the recent lift-off of policy rates in the United States_-also has negative distributional consequences.

To answer this question, we proceed in two steps (following a procedure used by Zdzienicka and others, 2015, in a different context). First, using Equation (2), we decompose the monetary policy shocks as the difference between innovations in policy rates (that is, the forecast error in policy rates) and innovations in policy rates that are driven by growth and inflation news, that is, the predicted value of equation (2). Second, we modify Equation (3) by using these two shocks and allowing the response of inequality to these shocks to be different. In particular, the follow specification is estimated:

$y_{i, t+k}-y_{i, t}=\alpha_{i}^{k}+\vartheta_{t}^{k}+\beta_{1}^{k} \widehat{F E_{l, t}}+\beta_{2}^{k} F E_{i, t}+\pi^{k} X_{i, t}+\varepsilon_{i, t}^{k}$,

where $F E$ is the forecast error in policy rates, $\widehat{F E}$ is its predicted value, and the difference between these two variables is the monetary policy shock considered in the analysis $(M P)$.

The results of estimating Equation (5) suggest that changes in policy rates that are driven by changes in economic activity (i.e. changes in $\widehat{F E_{l, t}}$ ) are associated with a decrease in inequality (Figure 9, Panel A). While this result is likely driven by the effect of improved economic conditions on inequality rather than the effect of changes in the policy rate per se-and therefore should not be interpreted as a causal effect — it is still informative for the debate on the effect of the current lift-off in policy rates in some economies, including the United States. In contrast, the results suggest that unanticipated changes in policy rates (the forecast errors in policy rates), either driven by economic developments or exogenous, increase inequality in the short and medium term, even though their effect on inequality is smaller than for unanticipated exogenous changes (Figure 9, Panel B). 
Finally, we look at the response of inequality to changes in the policy rates themselves (i.e. to changes in $S T_{t}^{i}$ rather than to their forecast errors). The results presented in Figure 9 panel C show that the response of inequality to a 100 basis point increase in the policy rate is positive but much smaller — only about 0.14 percent after a year of the shock — and less persistent than the one in the baseline. As discussed before, this smaller effect is likely to be the result of two sources of bias. The first is that changes in policy rates may well be driven by changes in economic activity, and hence may reflect the impacts of activity on inequality and not purely that of the policy rate. The second is monetary policy foresight: agents may receive news about changes in monetary policy in advance and alter their consumption and investment behaviour well before the changes take place.

\section{Role of Macroeconomic Conditions}

\section{Role of business cycle}

An interesting question is whether the effect of monetary policy shocks on inequality depends on the state of the business cycle. Previous empirical evidence regarding the effect of monetary policy on economic activity suggests that while the effects of monetary policy tightening are larger in periods of economic expansions, monetary policy easing has only effects in times of recessions (see, for example, Barnichon and Matthes 2015). Are there similar asymmetric effects of monetary policy shock on inequality?

To answer this question, we estimate the following specification:

$y_{i, t+k}-y_{i, t}=\alpha_{i}^{k}+\vartheta_{t}^{k}+\beta_{1}^{k} G\left(z_{i t}\right) M P_{i, t}+\beta_{2}^{k}\left(1-G\left(z_{i t}\right)\right) M P_{i, t}+\varepsilon_{i, t}^{k}$,

with 
$G\left(z_{i t}\right)=\frac{\exp \left(-\gamma z_{i t}\right)}{1+\exp \left(-\gamma z_{i t}\right)}, \quad \gamma>0$

in which $z$ is an indicator of the state of the economy normalized to have zero mean and unit variance, and $\mathrm{G}\left(\mathrm{z}_{\mathrm{it}}\right)$ is the corresponding smooth transition function between states. ${ }^{12}$ Our analysis uses contemporaneous GDP growth as a measure of the state of the economy. The identifying assumption is that monetary policy shocks do not affect whether the economy remains in either recession or expansion at the time of the shock. ${ }^{13}$

As discussed in Auerbach and Gorodnichenko (2013a, 2013b), the local projections approach to estimating non-linear effects is equivalent to the smooth transition autoregressive (STAR) model developed by Granger and Teräsvirta (1993). The main advantage of the local projection approach compared to estimating SVARs for each regime is that it uses a larger number of observations to compute the impulse response functions of only the dependent variables of interest, improving the stability and precision of the estimates. This estimation strategy can also more easily handle the possible correlation of the standard errors within countries, by clustering at the country level. ${ }^{14}$

The results of this exercise suggest that monetary policy shocks tend to have, on average, larger effects on inequality during periods of expansions than in recessions (Figure 10, Panel A

\footnotetext{
${ }^{12}$ Following Auerbach and Gorodnichenko (2012), we use $\gamma=1.5$ for the analysis of recessions and expansions.

${ }^{13}$ This finding is robust to different specifications (interacting the shock with a recession dummy instead of a transition function of the state of the economy), definitions of recessions (recessions defined as periods of negative growth or when growth is below the country average GDP growth) and to the use of lagged growth to construct the smooth transition function across states, thus relaxing the assumption that monetary policy shocks do not affect the state of the economy at time $t$.

${ }^{14}$ The standard errors of the estimated coefficients discussed below are even smaller if we allow for correlation in the standard errors across countries and cluster at the time level.
} 
and B). The results, however, mask significant heterogeneity in the response of inequality to positive and negative shocks during the business cycle. In particular, estimating equation (6) separately for positive and negative shocks suggest that while positive shocks have larger effects in periods of economic expansions (Figure 10, Panel C and D), negative shocks have larger effects during recessions (Figure 10, Panel E and F). ${ }^{15}$

\section{Role of labor earnings}

As discussed in the introduction, an important channel through which an increase in monetary policy rates can lead to an increase in inequality is the heterogeneity in labor earnings. In particular, since labor earnings at the bottom of the distribution are most affected by changes in economic activity (Heathcote and others 2010), an increase in policy rates would lead to an increase in inequality. Therefore, if this channel is effective, one should expect that, other things equal, the effect of monetary policy shocks on inequality is larger in countries with a higher share of labor earnings.

To test this hypothesis, we re-estimate a specification similar to equation (6), in which $\mathrm{z}$ is a normalized variable of the share of labor income in total income. ${ }^{16}$ The results in Figure 11 show that the effect of monetary policy shocks on inequality - in the first five years after the shock - is larger in countries with higher labor shares than in countries with relatively lower shares. These results suggest that earnings heterogeneity seems to be a major factor in transmitting the effect of monetary policy shocks on inequality.

\footnotetext{
15 The effects are similar when these interactions are jointly estimated.

${ }^{16}$ We consider the time-average to reduce endogeneity due to the possible effect on inequality on the share labor income.
} 


\section{Role of redistribution policies}

Finally, we test whether the effect of monetary policy shocks on inequality depends on the size of redistribution policies. To examine this issue, we re-estimate a specification similar to equation (6), in which $z$ is a normalized variable of the level of redistribution, proxied by the difference between market and net inequality. The results indeed suggest that redistribution policies matter (Figure 12). In particular, while the effect of monetary policy shocks on inequality is positive and statically significant in countries with relatively limited redistribution policies (that is, those with redistribution below the average in the distribution of redistribution in the sample), the effect is not statistically significantly different from zero in countries with relatively high redistribution. ${ }^{17}$

\section{WEALTH INEQUALITY}

Monetary policy can affect inequality through its impact on asset prices. The effect depends on how monetary policy affects different asset (equity, bond, and housing) prices, and how the price increase in these different assets affects inequality — which ultimately depends on the composition of the balance sheet of each household. As found by O'Farrell and others (2016) for 8 advanced economies and Adam and Tzamouranis (2016) for euro area countries, the effect of asset price inflation on inequality varies markedly across assets: (i) bond prices do not have significant effects on inequality; (ii) equity price inflation increases wealth inequality; (iii) while house price inflation reduces inequality, with the magnitude of the effect being in absolute value larger than for a same-size increase in equity prices.

\footnotetext{
${ }^{17}$ Similar results are obtained by splitting the sample in countries with inequality above average (median) inequality and countries with inequality below average.
} 
Based on these findings, an alternative way to infer about the effect of monetary policy shocks on wealth inequality in the absence of sufficiently long time series data for wealth inequality is to examine the response of housing and equity prices to monetary policy shocks.

The results of this exercise, obtained by estimating equation (3) alternatively using these variables as a dependent variable, are presented in Figure 13. They show that monetary policy tightening increases housing prices and reduces equity prices in the short-term, while it reduces housing and equity price by a similar about in the medium-term. While it is hard to infer the full effect of monetary policy shocks on wealth inequality based on these results, they seem to suggest - together with previous findings on the effect of housing and equity prices on inequality — that expansionary monetary policy increases wealth inequality in the short term but decreases it in the medium term.

\section{CONCLUSIONS}

Rising inequality and the accommodative monetary policy stance in many advanced economies have brought the role of conventional and unconventional monetary policy in affecting inequality to the forefront of the policy discussion. In particular, concerns have risen that the recent accommodative monetary policy stance in many advanced economies may negatively affect income and wealth distribution (Acemoglu and Johnson 2012; Stiglitz 2015).

We shed light on this issue by estimating the causal effect of monetary policy shocks on inequality for a panel of 32 advanced and emerging market economies and find that expansionary monetary policy reduces inequality. In particular, using unexpected changes in monetary policy rates that are orthogonal to innovations in economic activity, we find that an unexpected decrease of 100 basis points in the policy rate reduces inequality by about $1 \frac{1 / 4}{4}$ percent in the short term and by about $2 \frac{1 / 4}{4}$ percent in the medium term. The effect is also economically significant, given the high persistence and limited variation in the Gini coefficient. In particular, 
the magnitude of the medium-term effect is approximately equivalent to a standard deviation of the change in the Gini coefficient (2.4 percent) in the sample. The effect, however, varies over time, depending on the type of the shocks (tightening versus expansionary monetary policy) and the state of the business cycle, and across countries depending on the initial level of inequality and share of labor income. In particular, we find that the effect is larger for positive monetary policy shocks, especially during expansions. Looking across countries, we find that the effect is larger in countries with higher labor share of income and smaller redistribution policies. Finally, while an unexpected increase in policy rates increases inequality, changes in policy rates driven by an increase in growth are associated with lower inequality. 


\section{References}

Acemoglu, Daron and Simon Johnson (2012) 'Who Captured the Fed?', New York Times, 29. Auerbach, Alan, and Yuriy Gorodnichenko. 2013a. "Fiscal Multipliers in Recession and Expansion.” In Fiscal Policy After the Financial Crisis, eds. Alberto Alesina and Francesco Giavazzi, NBER Books, National Bureau of Economic Research, Inc., Cambridge, Massachusetts.

—. 2013b. "Measuring the Output Responses to Fiscal Policy." American Economic Journal: Economic Policy 4 (2): 1-27.

Ben Zeev, Nadav, and Evi Pappa. 2014. "Chronicle of a War Foretold: The Macroeconomic Effects of Anticipated Defense Spending Shocks.” CEPR Discussion Paper 9948, Centre for Economic Policy Research, London.

Bernanke, B. S. (2015), "Monetary Policy and Inequality” available at http://www.brookings.edu/blogs/ben-bernanke/posts/2015/06/01-monetary-policy-andinequality.

Bernanke, B. S., and K. N. Kuttner (2005), "What explains the stock market's reaction to Federal Reserve policy?”, The Journal of Finance, Vol. 60/3, pp. 1221-1257.

Bitler, M. and H. Hoynes (2015) 'Heterogeneity in the Impact of Economic Cycles and the Great Recession: Effects Within and Across the Income Distribution', American Economic Review, Papers and Proceedings 2015, 105(5): 154-160.

Bivens, Josh (2015) 'Gauging the impact of the Fed on inequality during the Great Recession', Brookings Institution Working Paper. 
Card, D. (2001), "The effect of unions on wage inequality in the U.S. labor market," Industrial and Labor Relations Review, Vol. 54(2), pp. 296-315.

Claeys, Grégory (2014) 'The (not so) Unconventional Monetary Policy of the European Central Bank since 2008', paper for the Monetary Dialogue discussions in the Economic and Monetary Affairs Committee (ECON) of the European Parliament,

Claeys, Grégory, Zsolt Darvas, Alvaro Leandro and Thomas Walsh (2015)" The effects of UltraLoose Monetary Policies on inequalities," Policy Contribution 2015/09, Bruegel.

Coibion, O. "Are the Effects of Monetary Policy Shocks Big or Small?", American Economic Journal: Macroeconomics, Vol. 4, No. 2 (April 2012), pp. 1-32.

Coibion, O., Y. Gorodnichenko, L. Kueng and J. Silvia (2012) 'Innocent bystanders? Monetary policy and inequality in the US', Working Paper 18170, National Bureau of Economic Research.

Doepke, M. and M. Schneider (2006), "Inflation and the redistribution of nominal wealth," Journal of Political Economy, Vol. 114/6, pp. 1069-1097.

Draghi, Marion (2016), "Stability, Equity and Monetary Policy” 2nd DIW Europe Lecture, http://www.ecb.europa.eu/press/key/date/2016/html/sp161025.en.html

Feenstra, R. and G. Hanson (2004), "Global production sharing and rising inequality: A survey of trade and wages", Chapter 6 of Part I in K. M. Choi and J. Harrigan (eds), Handbook of International Trade.

Forni, Mario, and Luca Gambetti. 2010. "Fiscal Foresight and the Effects of Government Spending." Centre for Economic Policy Research Discussion Paper 7840.

Guerello, Chiara (2016). "Conventional and Unconventional Monetary Policy vs. Household Income Distribution: An Empirical Analysis for the Euro Area," (mimeo). 
Jaumotte, F. and C. Osorio Buitron (2015), "Inequality and labor market institutions", IMF Staff Discussion Note, No. 15/14.

Karahan, F. and S. Ozkan (2013), "On the persistence of income shocks over the life cycle: Evidence, theory, and implications", Review of Economic Dynamics, Vol. 16/3, pp. 452476.

Leeper, Eric M., Alexander W. Richter, and Todd B. Walker. 2012. "Quantitative Effects of Fiscal Foresight.” American Economic Journal: Economic Policy 4 (2): 115-44.

Leeper, Eric M., Todd B. Walker, and Shu-Chun S. Yang. 2013. "Fiscal Foresight and Information Flows." Econometrica 81 (3): 1115-45.

O’Farrell, R., Ł. Rawdanowicz and K. Inaba (2016), "Monetary Policy and Inequality", OECD Economics Department Working Papers, No. 1281, OECD Publishing, Paris. DOI:

Saiki, A. and J. Frost (2014) 'Does unconventional monetary policy affect inequality? Evidence from Japan', Applied Economics, 46(36), 4445-4454.

Stiglitz, J. (2015) 'New theoretical perspectives on the distribution of income and wealth among individuals: Part IV: Land and Credit', Working Paper 21192, National Bureau of Economic Research.

Yellen, J. (2014), "Perspectives on inequality and opportunity from the survey of consumer finances", speech at the Conference on Economic Opportunity and Inequality, Federal Reserve Bank of Boston, Boston, Massachusetts, October 17.

Zdzienicka, A., S. Chen, F. Diaz Kalan, S. Laseen, and K. Svirydzenka (2015) "Effects of Monetary and Macroprudential Policies on Financial Conditions: Evidence form the United States", IMF Working Paper, 15/288. 
Figure 1. Evolution of Inequality (1990-2013)

Inequality in Net Income (1990-2013)

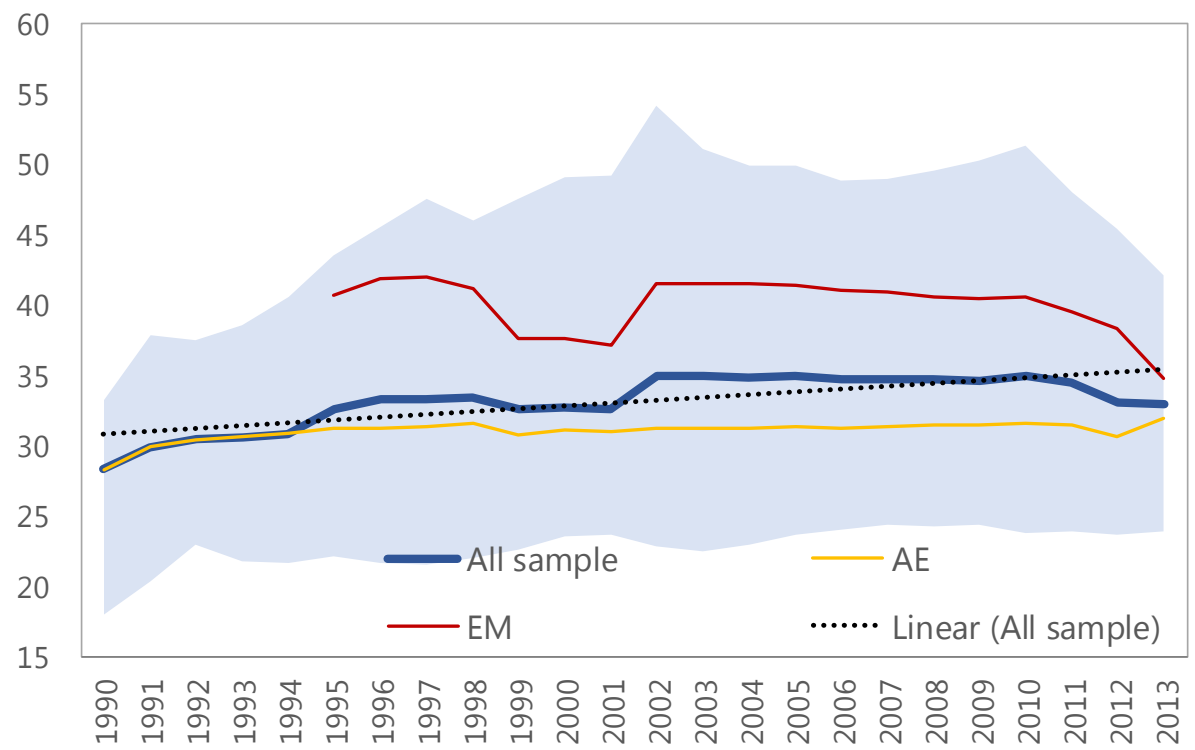

Note: Solid line indicates average mean estimates; shaded area indicates difference between minimum and maximum values. List of countries (Annex I) to complete. Source: Standardized World Income Inequality Database v5.0 (Solt, 2014)

\section{Inequality in Market Income (1990-2013)}

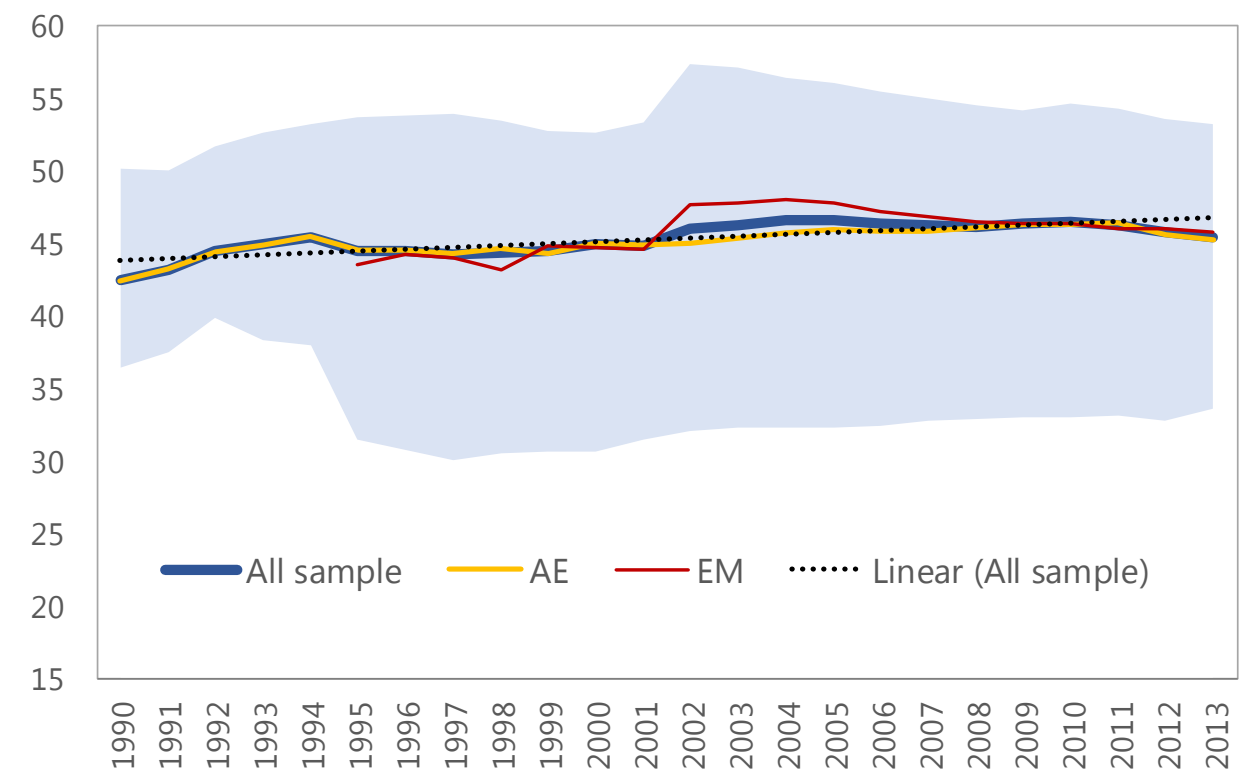

Note: Solid line indicates average mean estimates; shaded area indicates difference between minimum and maximum values. List of countries (Annex I) to complete. Source: Standardized World Income Inequality Database v5.0 (Solt, 2014) 


\section{Figure 2 Exogenous Monetary Policy Shocks for the United States}

(percentage points)

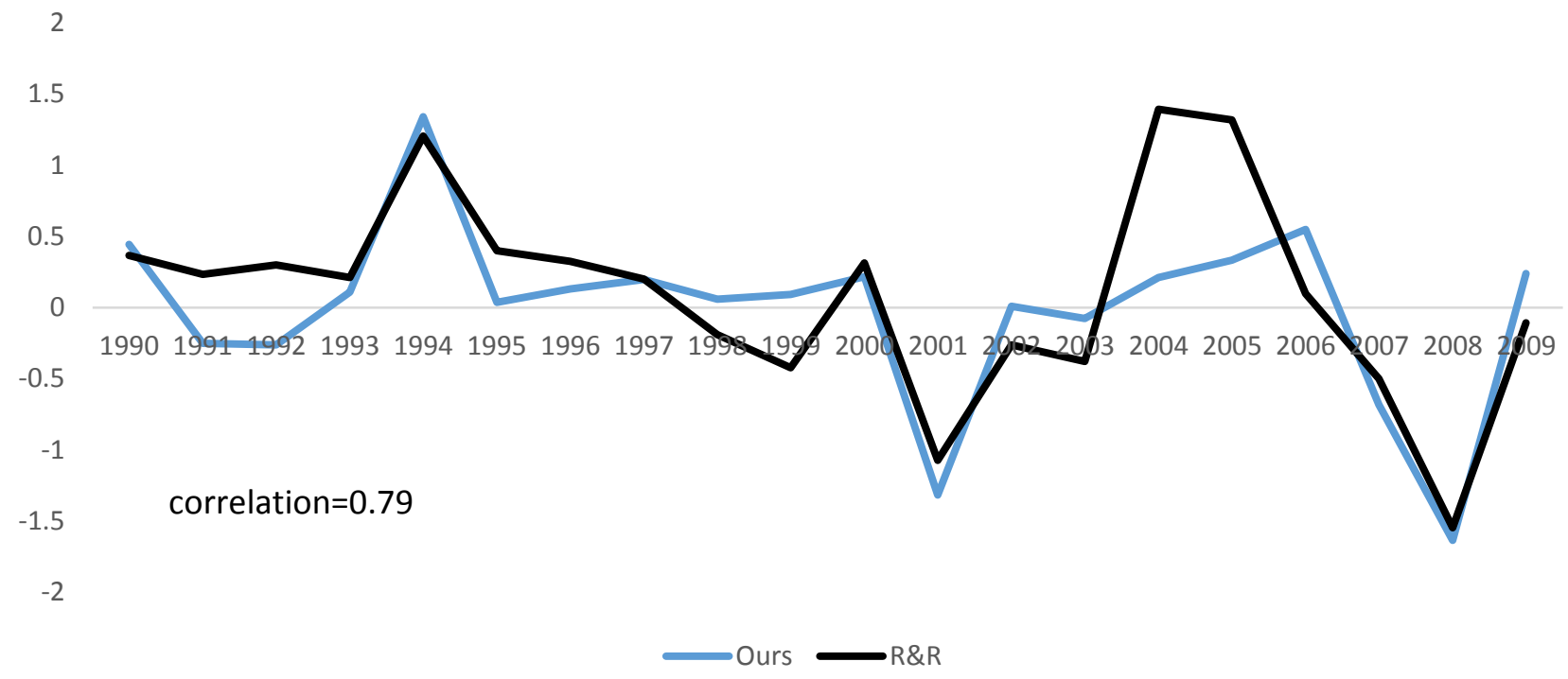

Note: "Ours" refers to the monetary policy shocks identified as in equations (1) and (2). "R\&R" refers to the monetary policy shocks identified by Romer and Romer (2004). 
Figure 3. The effect of monetary policy on output, unemployment and inflation

Panel A. Output (\%)

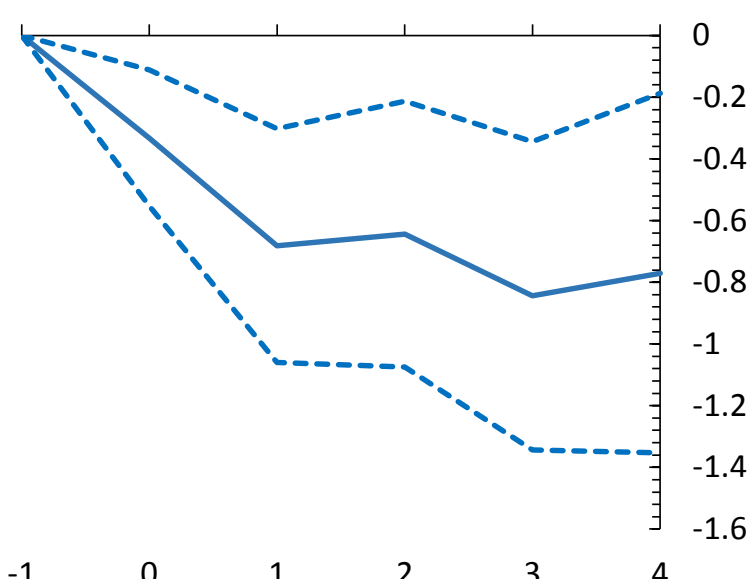

Panel B. Unemployment (ppt)

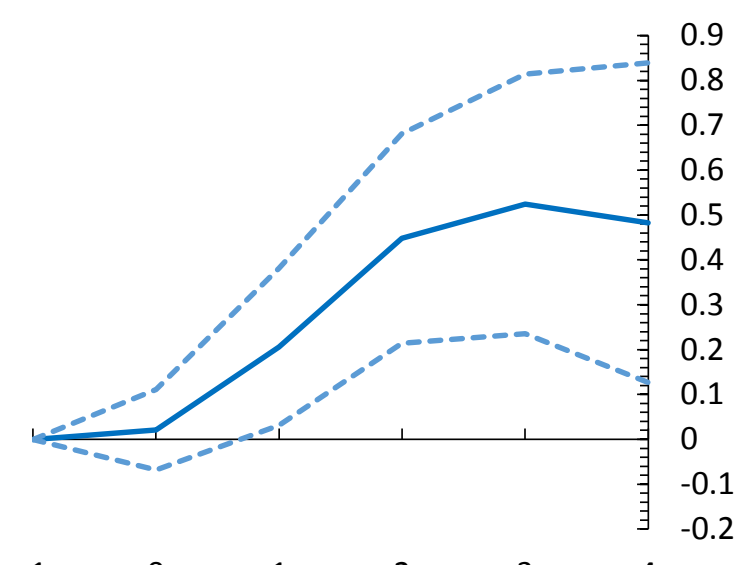

Panel C. CPI level (\%)

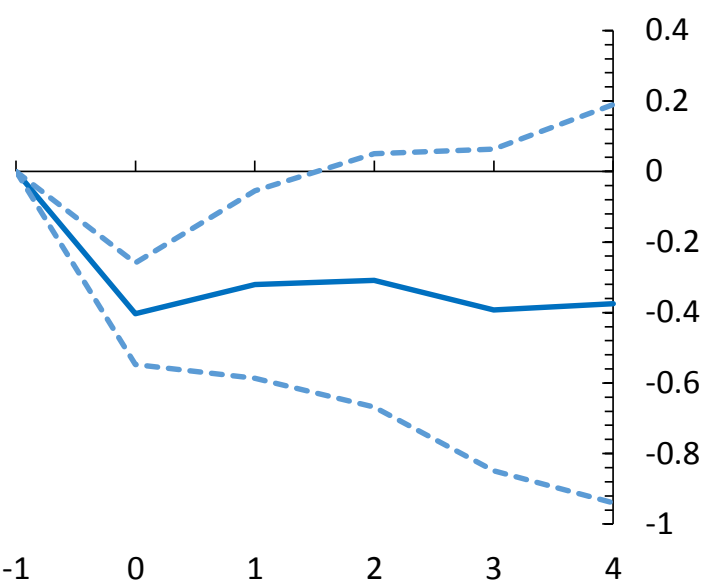

Note: $t=0$ is the year of the shock. Solid lines denote the response to an unanticipated increase in monetary policy rates of 100 basis points, and dashed lines denote 90 percent confidence bands. Estimates based on equation (3). 
Figure 4. The effect of monetary policy shocks on income inequality (Net Gini), 1990-2013

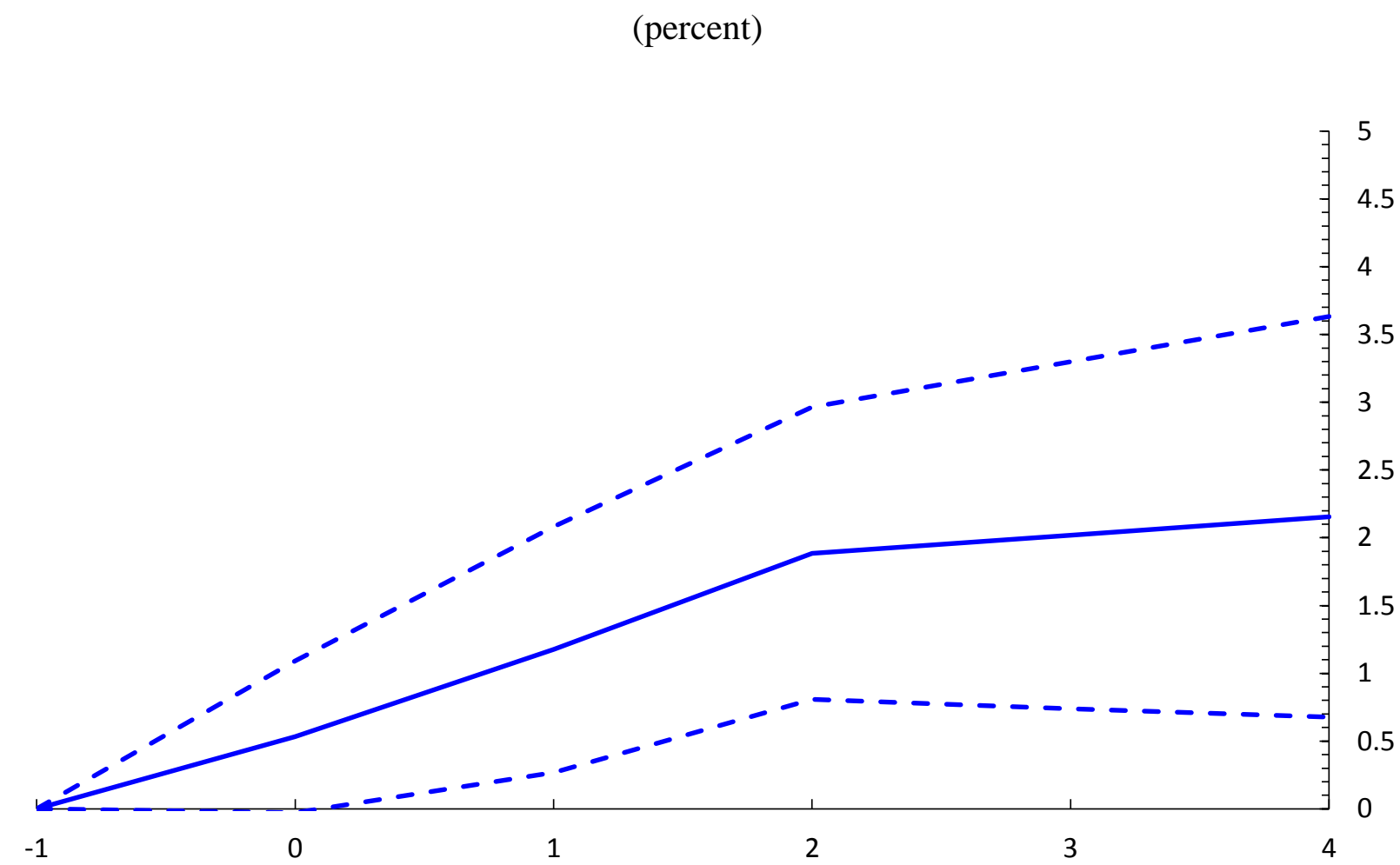

Note: $\mathrm{t}=0$ is the year of the shock. Solid lines denote the response to an unanticipated increase in monetary policy rates of 100 basis points, and dashed lines denote 90 percent confidence bands. Estimates based on equation (3). 
Figure 5. The effect of monetary policy shocks on income inequality, robustness checks

$$
\text { (percent) }
$$

Panel A. Gross Inequality

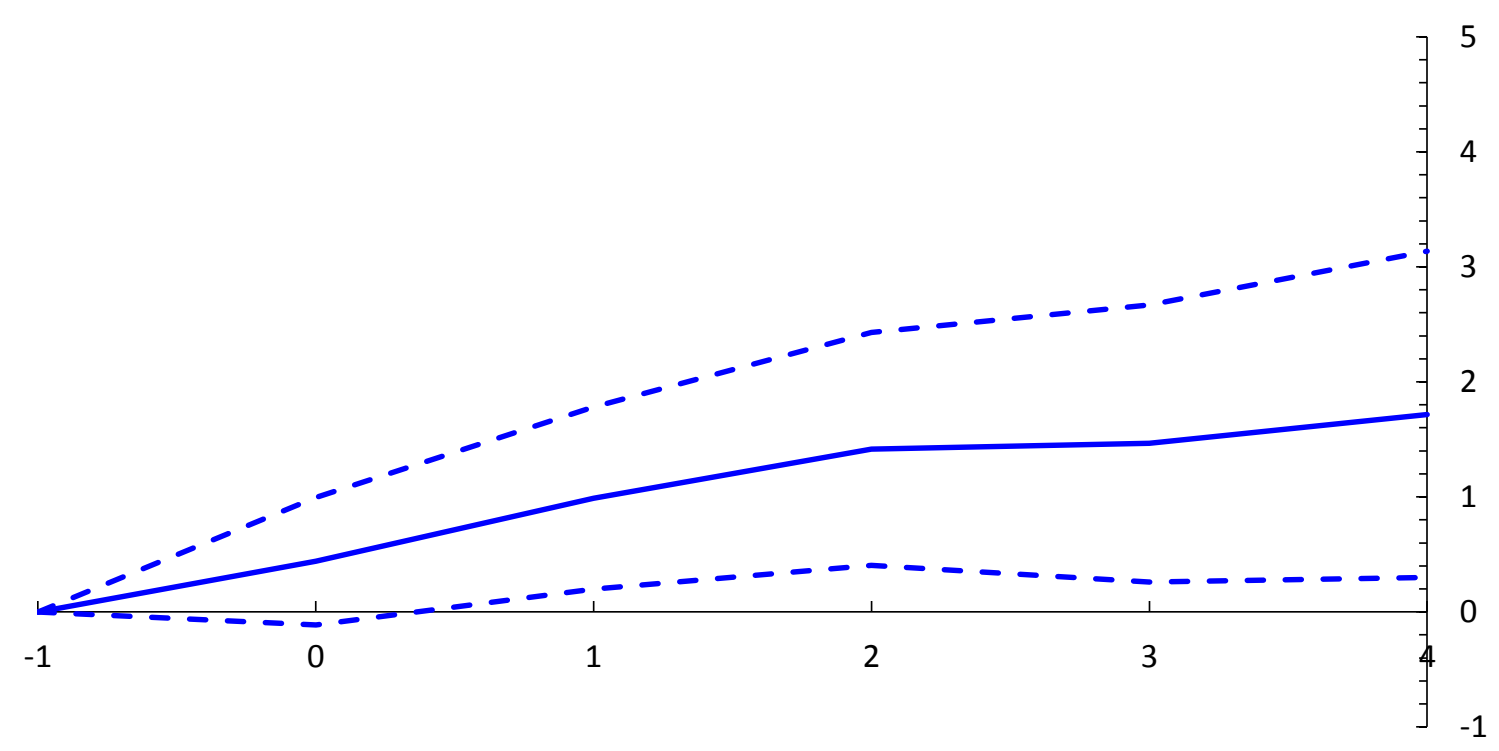

Panel B. Advanced economies

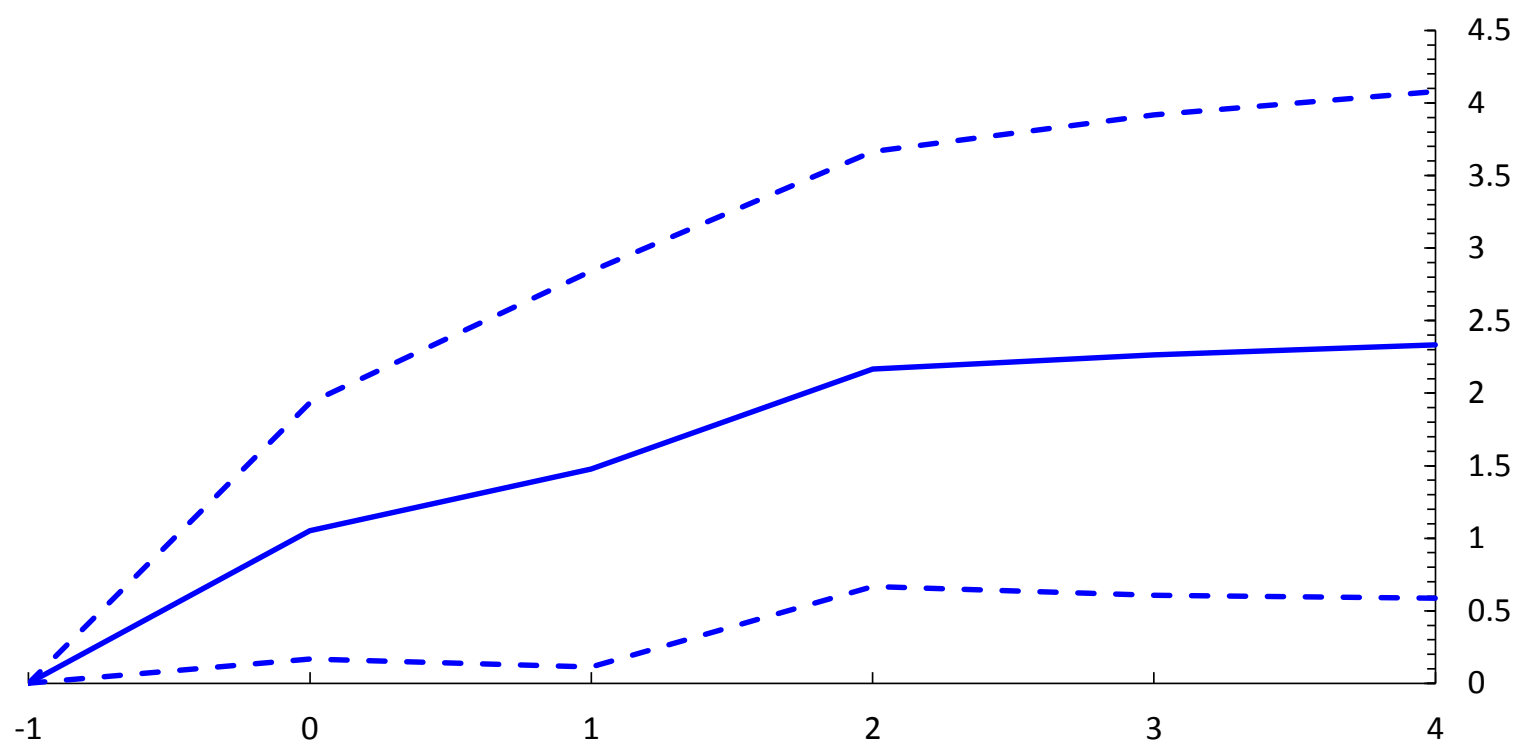




\section{Panel C. Pre-2008}

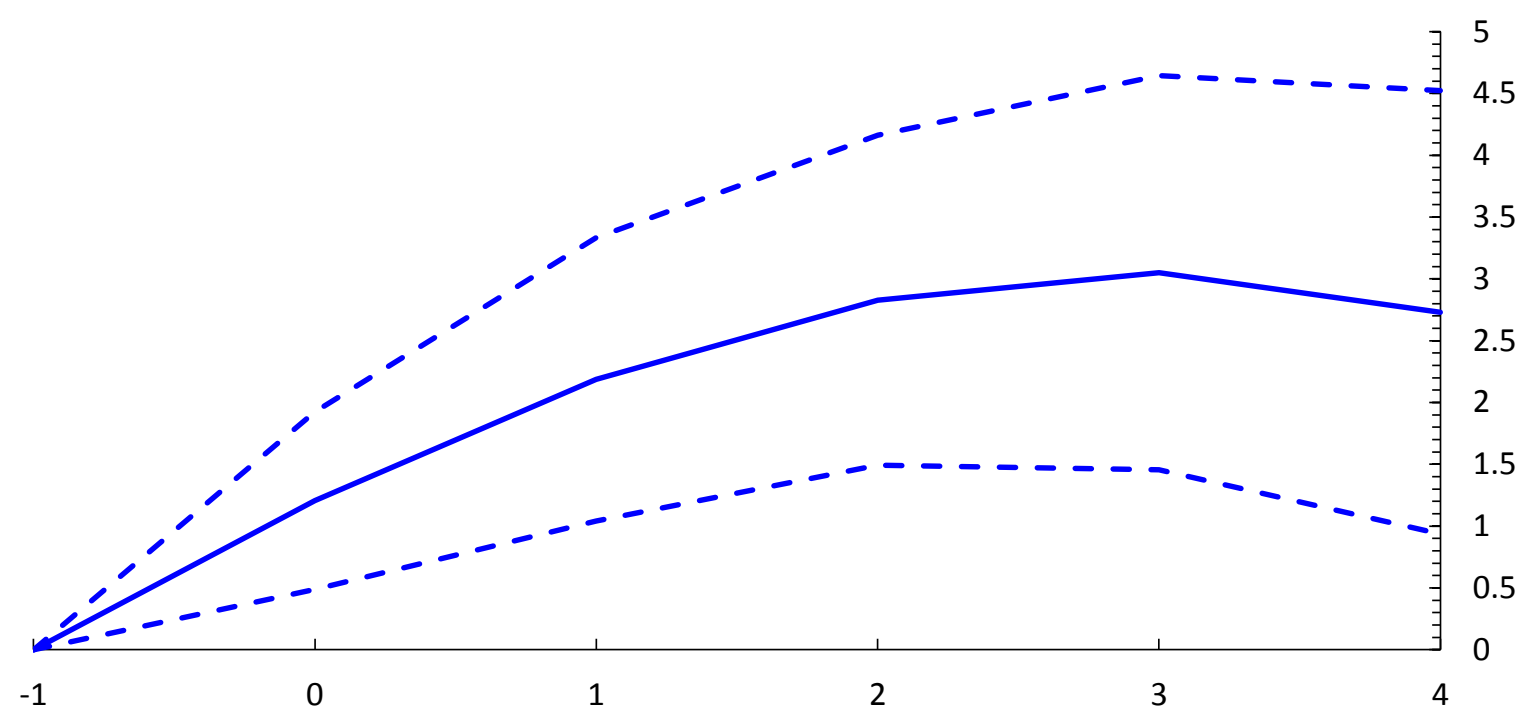

Panel D. Controlling for recessions and fiscal stance

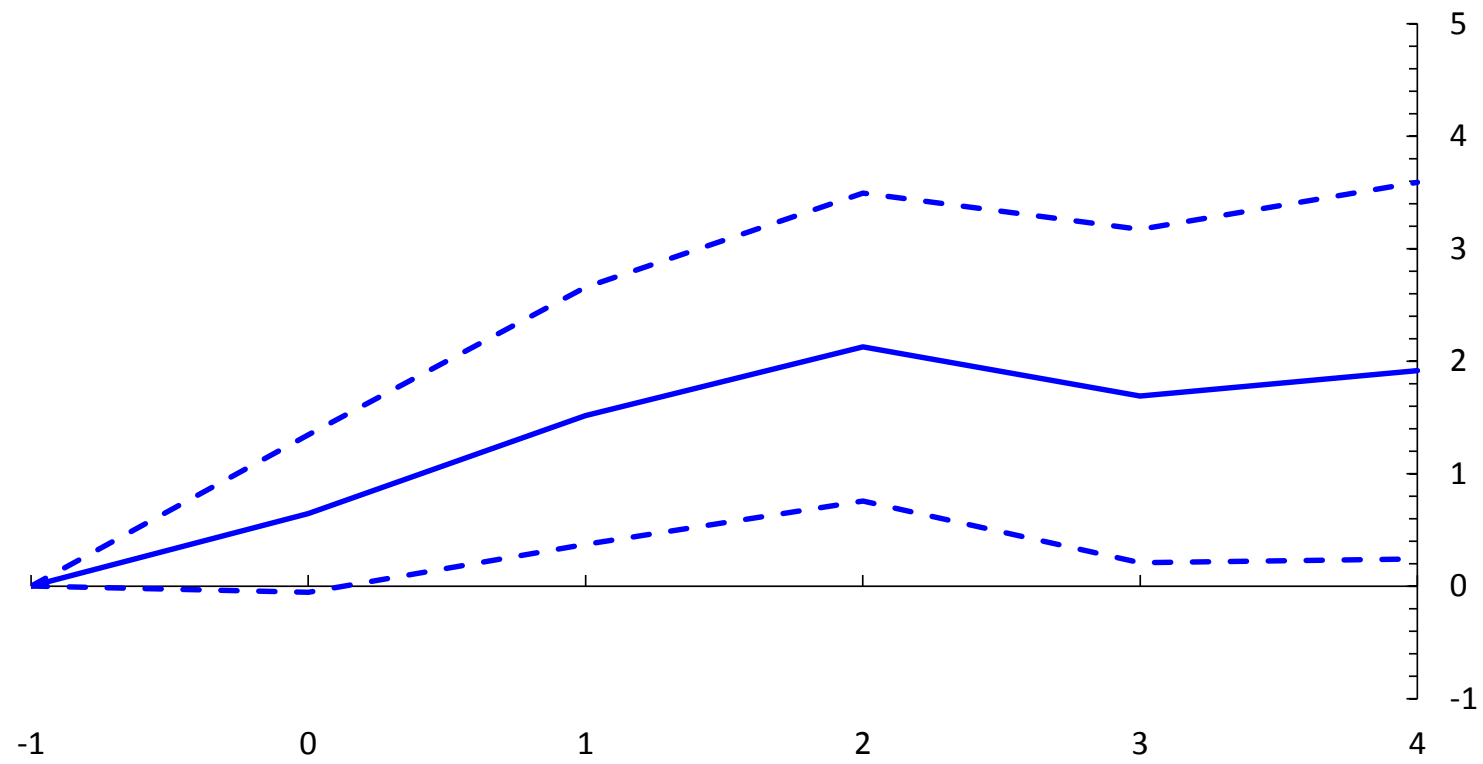

Note: $\mathrm{t}=0$ is the year of the shock. Solid lines denote the response to an unanticipated increase in monetary policy rates of 100 basis points, and dashed lines denote 90 percent confidence bands. Estimates based on equation (3). 


\section{Figure 6. The effect of monetary policy on top income shares}

(percentage points)

Panel A. Top 10 percent

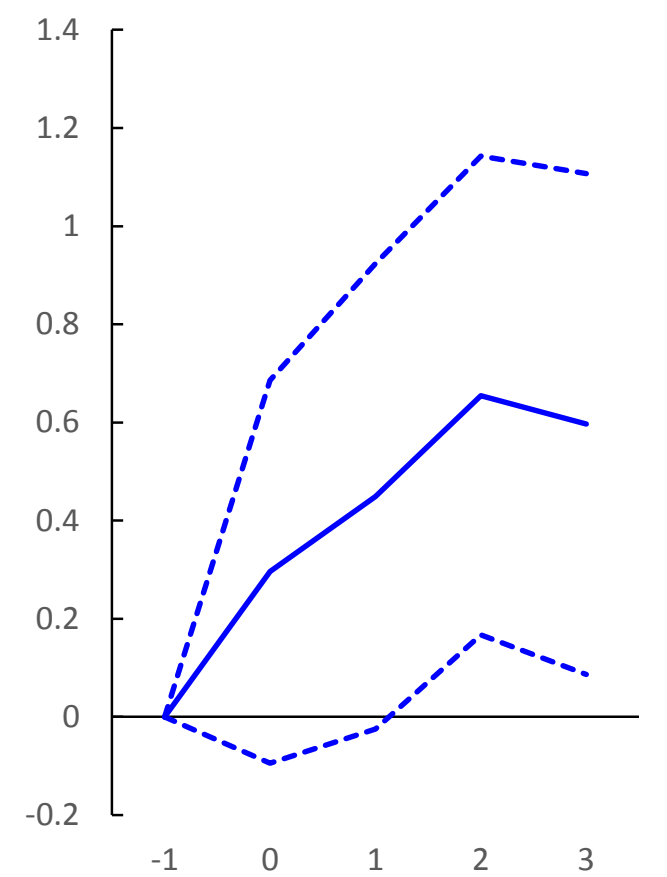

Panel B. Top 5 percent

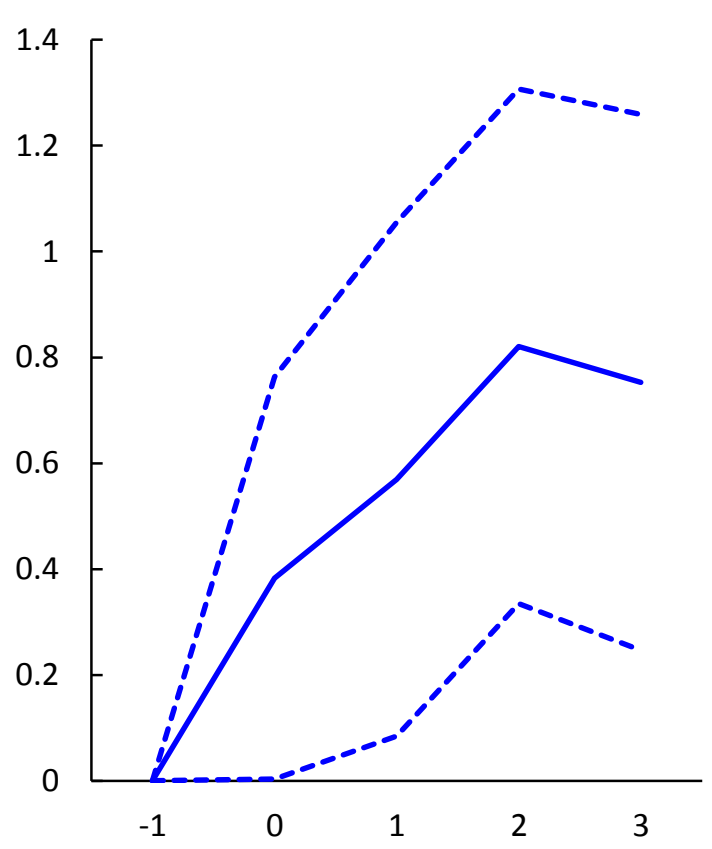

Panel C. Top 1 percent

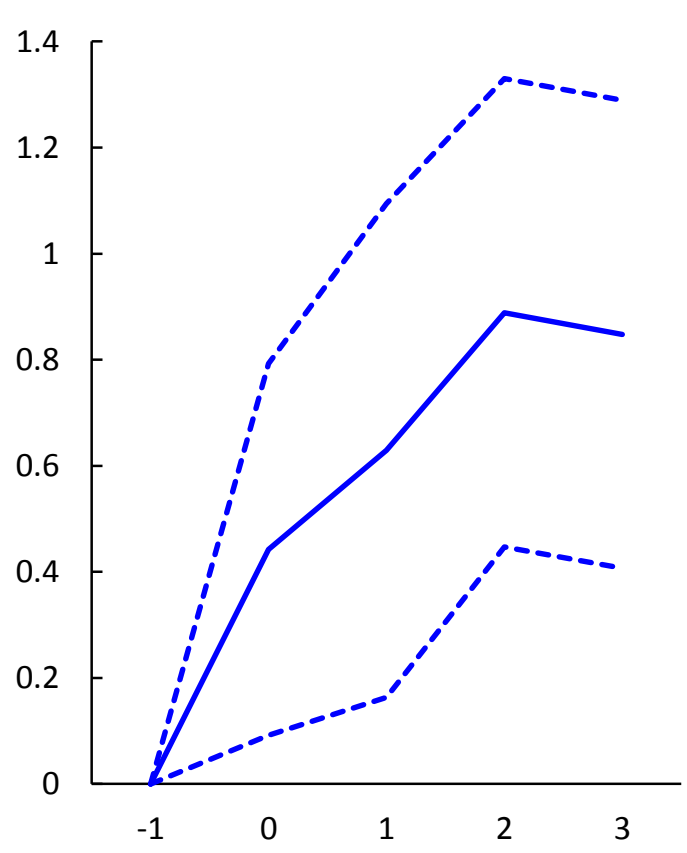

Note: $t=0$ is the year of the shock. Solid blue lines denote the response to an unanticipated positive (negative) monetary policy rates of 100 basis points, and dashed lines denote 90 percent confidence bands. Estimates based on equation (3). 
Figure 7. The effect of monetary policy shocks on the share of wage income in GDP

(percentage points)

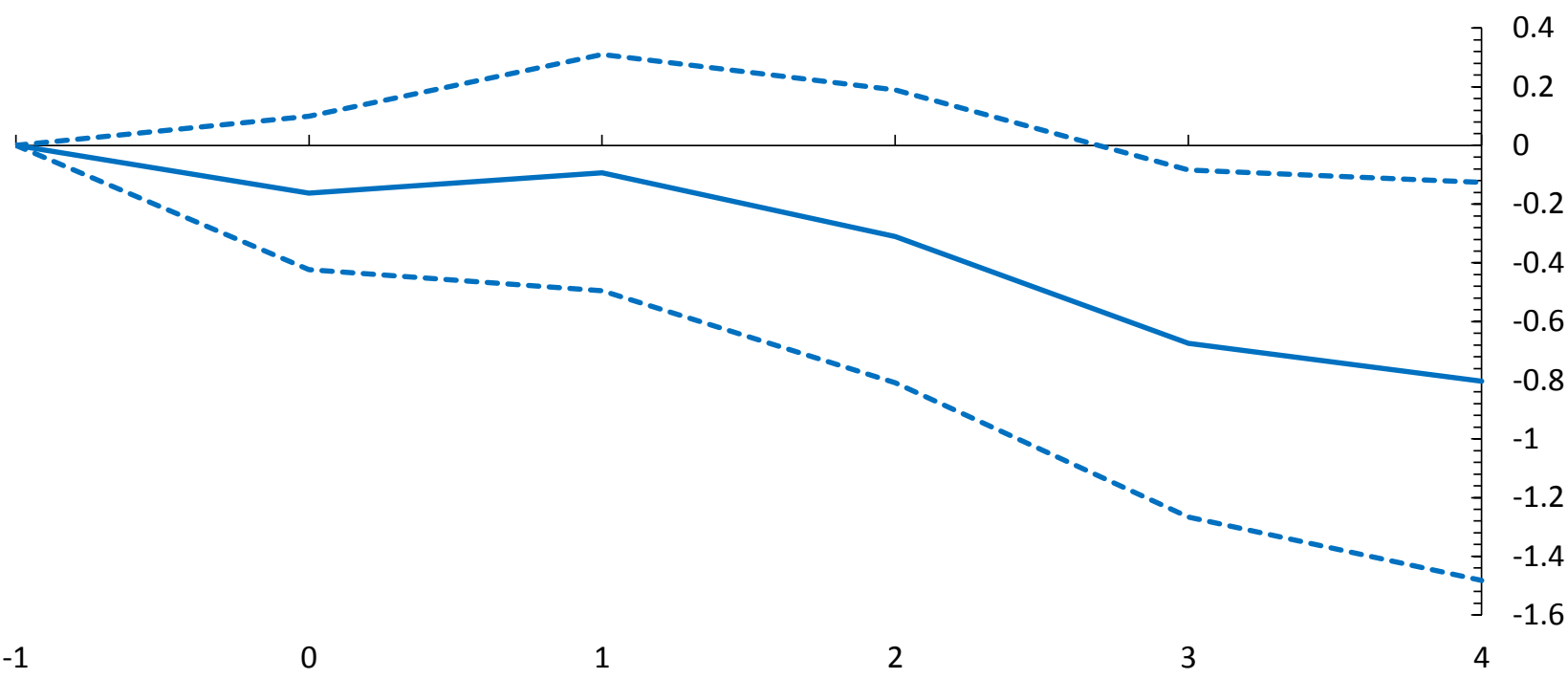

Note: $\mathrm{t}=0$ is the year of the shock. Solid lines denote the response to an unanticipated increase in monetary policy rates of 100 basis points, and dashed lines denote 90 percent confidence bands. Estimates based on equation (3). 


\section{Figure 8. The effect of monetary policy on income inequality, positive vs. negative shocks}

(percent)

Panel A. Negative monetary policy shocks

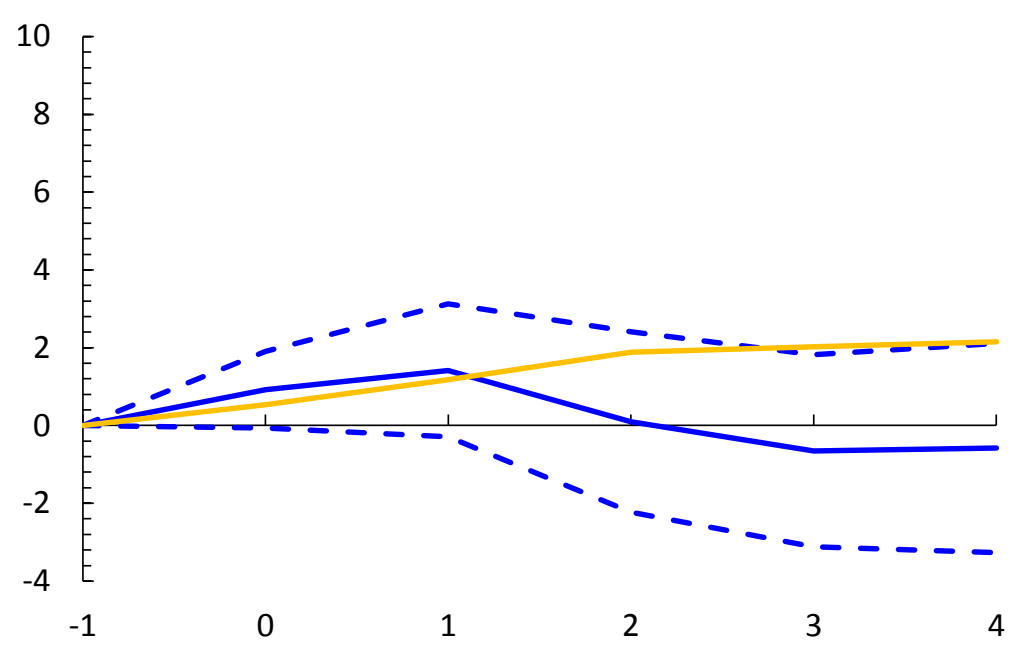

Panel B. Positive monetary policy shocks

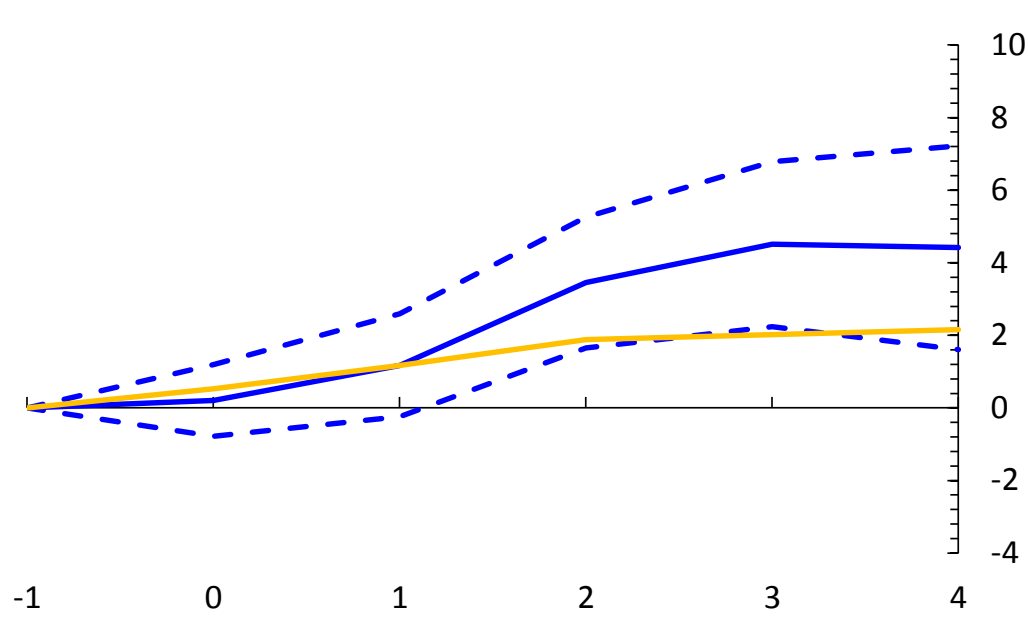

Note: $t=0$ is the year of the shock. Solid blue lines denote the response to an unanticipated positive (negative) monetary policy rates of 100 basis points, and dashed lines denote 90 percent confidence bands. Solid yellow lines denote the unconditional (baseline) response presented in Figure 3.2. Estimates based on equation (4) 


\section{Figure 9. The effect of monetary policy on income inequality, exogenous vs. growth driven shocks}

(percent)

Panel A. Growth-driven monetary policy shocks Panel B. Innovations in policy rates Panel C. Changes in policy rates

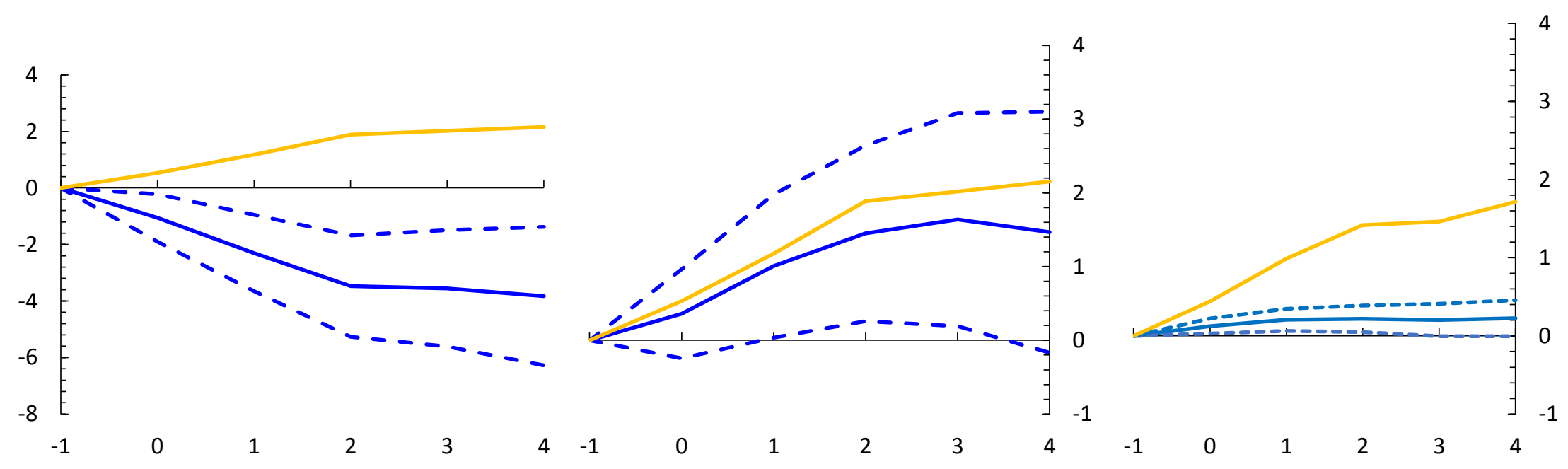

Note: $t=0$ is the year of the shock. Solid blue lines denote the response to, alternatively, a growth-driven increase, innovations or changes in monetary policy rates of 100 basis points; dashed lines denote 90 percent confidence bands. Solid yellow lines denote the unconditional (baseline) response presented in Figure 3.2. Growth-driven monetary policy shocks are identified as the forecast error in policy rates explained news in growth and inflation-that is, the fitted value of equation (2). Innovations in policy rates are the forecast error in policy rates. Estimates based on equation (5) 


\section{Figure 10. The effect of monetary policy on income inequality, the role of business cycle}

\section{(percent)}
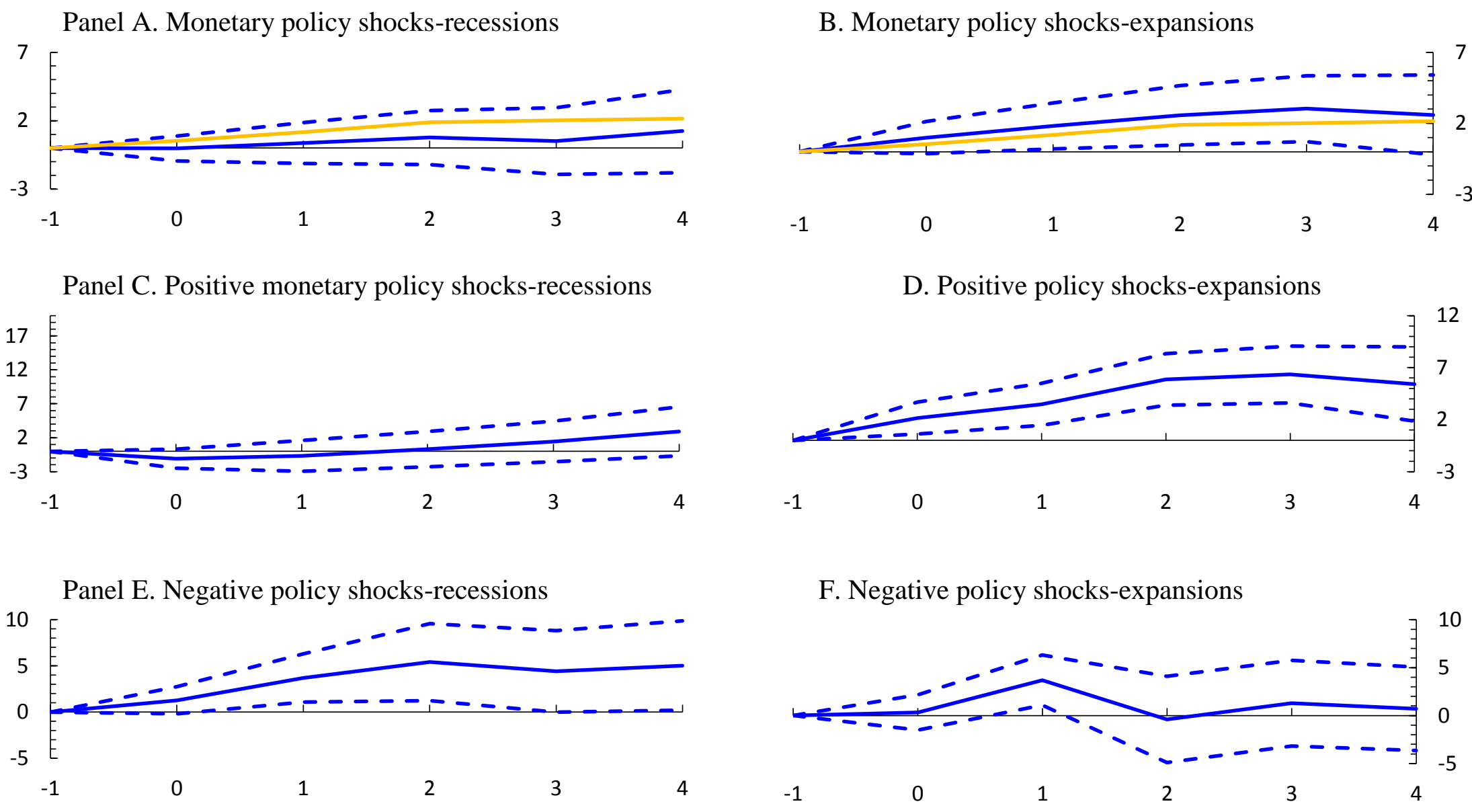

Note: $\mathrm{t}=0$ is the year of the shock. Solid blue lines denote the response to an unexpected increase (or decrease) in monetary policy rates of 100 basis points, and dashed lines denote 90 percent confidence bands. Solid yellow lines denote the unconditional (baseline) response presented in Figure 3.2. Estimates based on equation (6). 


\section{Figure 11. The effect of monetary policy on income inequality, the role of labor earnings}

\section{(percent)}

Panel A. Very low labor share

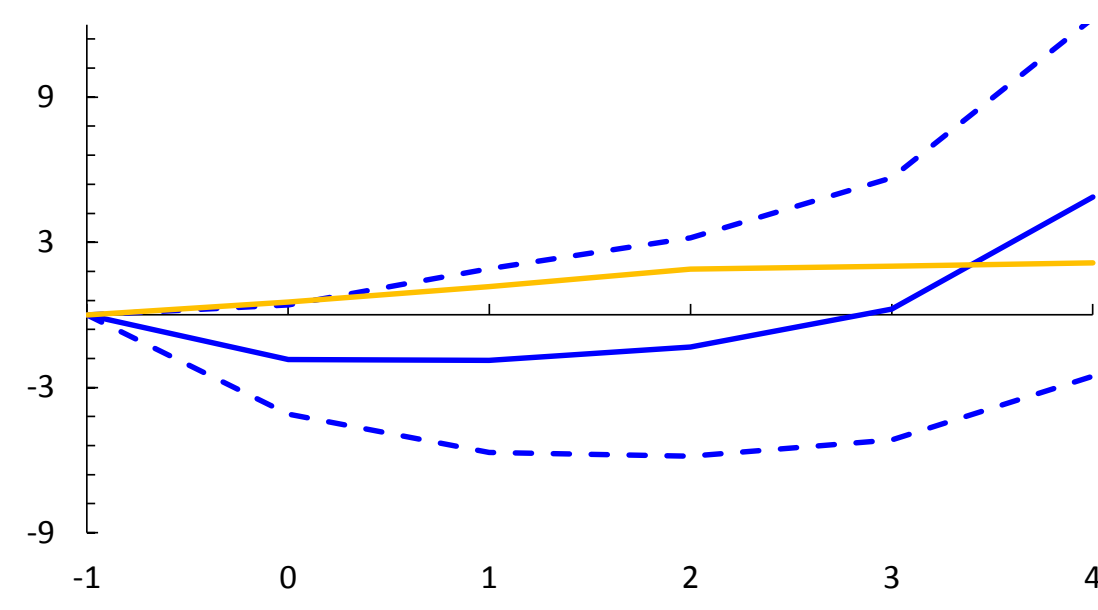

Panel B. Very high labor share

Note: $\mathrm{t}=0$ is the year of the shock. Solid blue lines denote the response to an unanticipated monetary policy rates of 100 basis points in countries with relatively higher (lower) inequality, and dashed lines denote 90 percent confidence bands. Solid yellow lines denote the unconditional (baseline) response presented in Figure 3.2. 


\section{Figure 12. The effect of monetary policy on income inequality, the role of redistribution}

(percent)

Panel A. Low redistribution

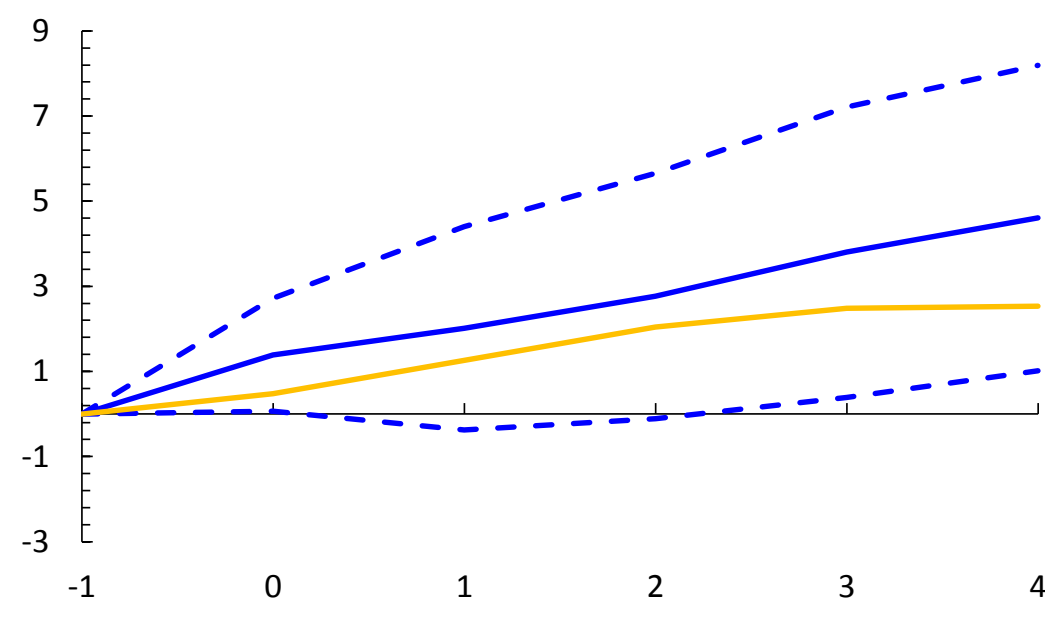

Panel B. Low initial equality

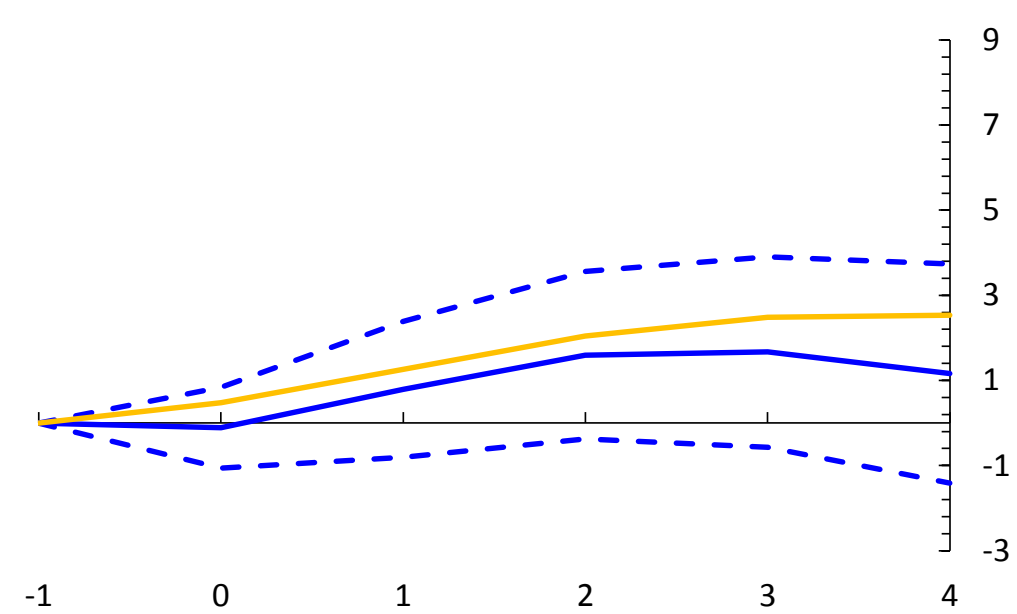

Note: $\mathrm{t}=0$ is the year of the shock. Solid blue lines denote the response to an unanticipated monetary policy rates of 100 basis points in countries with relatively higher (lower) inequality, and dashed lines denote 90 percent confidence bands. Solid yellow lines denote the unconditional (baseline) response presented in Figure 3.2. 


\section{Figure 13. The effects of monetary policy shocks on equity and house price index}

(percent)

Panel A. Housing prices

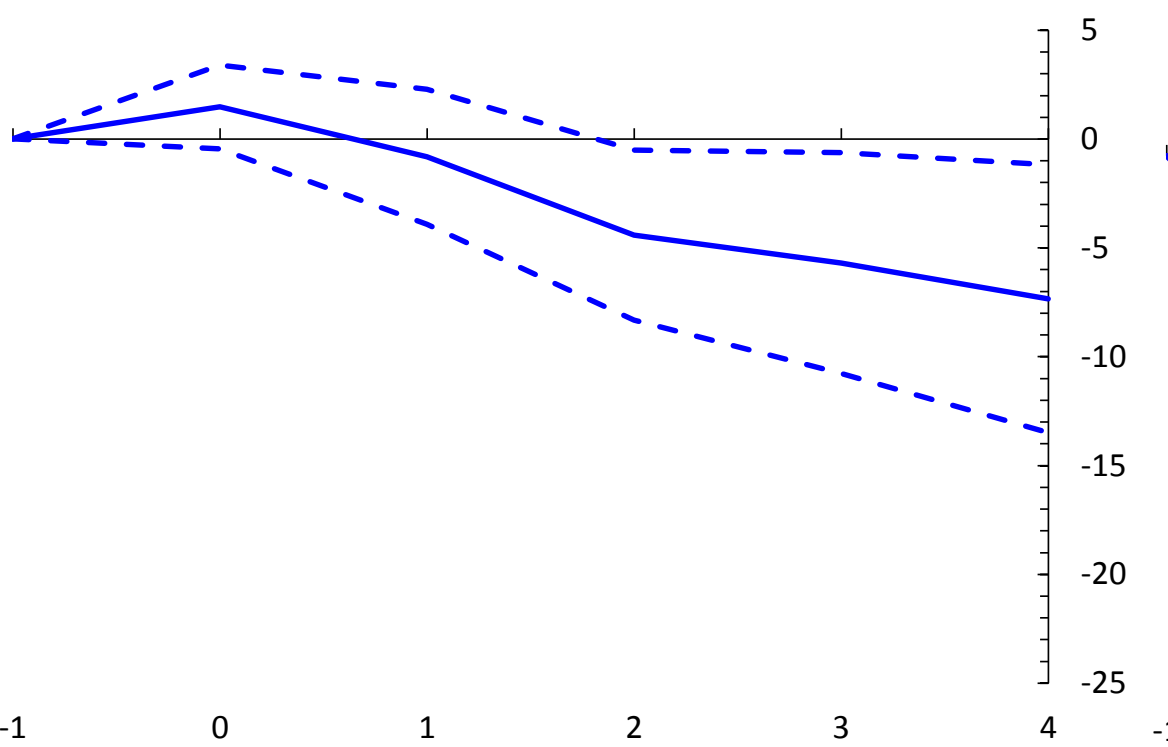

Panel B. Equity prices

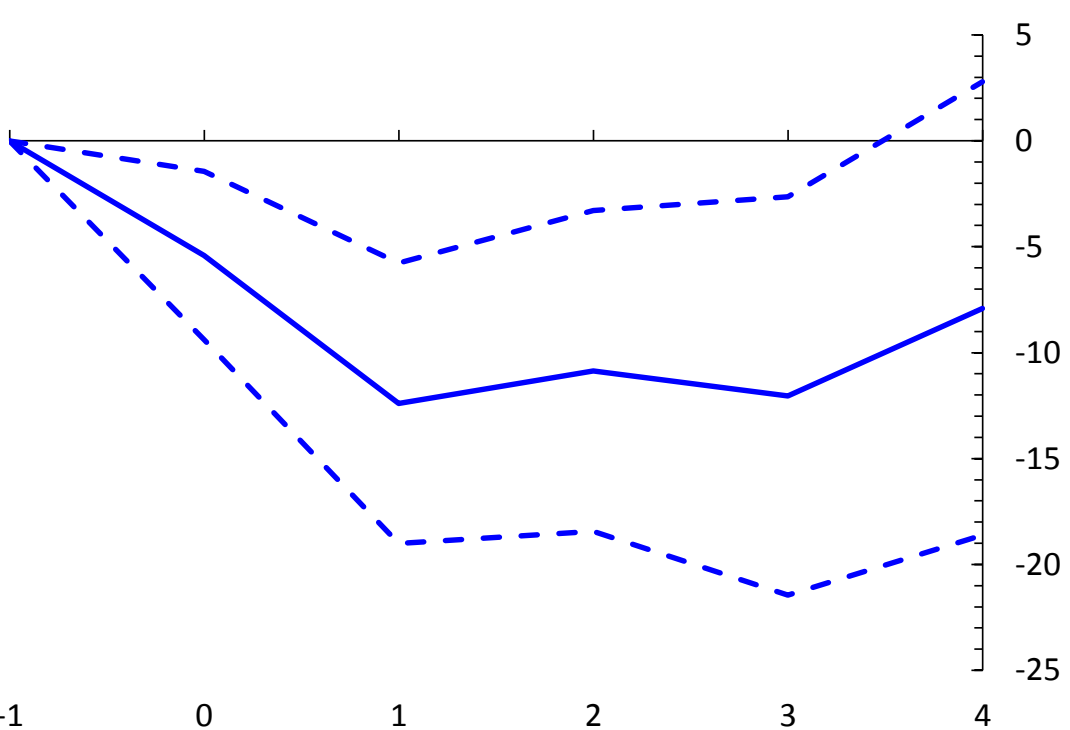

Note: $t=0$ is the year of the shock. Solid blue lines denote the response to an unanticipated monetary policy rates of 100 basis points, and dashed lines denote 90 percent confidence bands. 
Table1. Descriptive statistics

\begin{tabular}{|c|c|c|c|c|}
\hline & Mean & SD & Min & Max \\
\hline Inequality & & & & \\
\hline Net Gini & 33.6 & 7.2 & 18.0 & 54.1 \\
\hline Gross Gini & 45.5 & 5.2 & 30.0 & 57.3 \\
\hline Top income shares & & & & \\
\hline Top 1 percent & 11.1 & 4.3 & 5.2 & 23.5 \\
\hline Top 5 percent & 24.6 & 5.7 & 14.6 & 38.8 \\
\hline Top 10 percent & 35.9 & 6.6 & 23.6 & 50.6 \\
\hline Share of wage income in GDP & 51.5 & 4.0 & 39.2 & 58.8 \\
\hline Monetary policy shocks & 0.0 & 1.13 & -3.9 & 4 \\
\hline
\end{tabular}


Table 2. The effect of monetary policy shocks on income inequality (Net Gini), 1990-2013

\begin{tabular}{lccccc}
\hline \multirow{2}{*}{ Gini growth(t-1) } & $\mathbf{K = 0}$ & $\mathbf{K = 1}$ & $\mathbf{K = 2}$ & $\mathbf{K = 3}$ & $\mathbf{K = 4}$ \\
\cline { 2 - 6 } & $0.176^{* *}$ & $0.266^{* *}$ & 0.080 & -0.074 & -0.175 \\
Gini growth(t-1) & $(2.16)$ & $(2.53)$ & $(0.58)$ & $(-0.49)$ & $(-1.12)$ \\
& 0.071 & -0.139 & $-0.274^{* *}$ & $-0.346^{* * *}$ & $-0.305^{* *}$ \\
& $(1.17)$ & $(-1.58)$ & $(-2.41)$ & $(-2.81)$ & $(-2.27)$ \\
Monetary policy shock (t) & & & & & \\
& 0.531 & $1.176^{* *}$ & $1.886^{* * *}$ & $2.018^{* * *}$ & $2.154^{* *}$ \\
Monetary policy shock (t-1) & $(1.56)$ & $(2.13)$ & $(2.88)$ & $(2.59)$ & $(2.40)$ \\
& 0.441 & 0.389 & 0.074 & 0.160 & 0.221 \\
Monetary policy shock (t-2) & $(1.62)$ & $(1.08)$ & $(0.16)$ & $(0.30)$ & $(0.34)$ \\
& -0.034 & -0.114 & 0.278 & 0.364 & 0.235 \\
& $(-0.16)$ & $(-0.36)$ & $(0.74)$ & $(0.84)$ & $(0.49)$ \\
& & & & & \\
$\mathrm{N}$ & & & & & 349 \\
$\mathrm{R}^{2}$ & 467 & 439 & 409 & 379 & 0.28 \\
\hline
\end{tabular}

Note: T-statistics based on robust clustered standard errors in parenthesis. $* * *, * * *$ denote significance at 1 percent, 5 percent and 10 percent, respectively. Estimates based on equation (3). 


\section{Annex}

Table A1. List of countries in the sample

\begin{tabular}{|l|l|}
\hline Advanced Economies & Emerging Market Countries \\
\hline Australia & Argentina \\
Canada & Brazil \\
Czech Republic & Chile \\
France & Hungary \\
Germany & India \\
Hong Kong SAR & Indonesia \\
Italy & Malaysia \\
Japan & Mexico \\
Korea & Philippines \\
Netherlands & Poland \\
New Zealand & Thailand \\
Norway & Turkey \\
Singapore & \\
Slovak Republic & \\
Spain & \\
Sweden & \\
Switzerland & \\
Taiwan Province of & \\
China & \\
United Kingdom & \\
United States & \\
\hline
\end{tabular}


Figure A1. Distribution of monetary policy shocks

\section{All Countries}

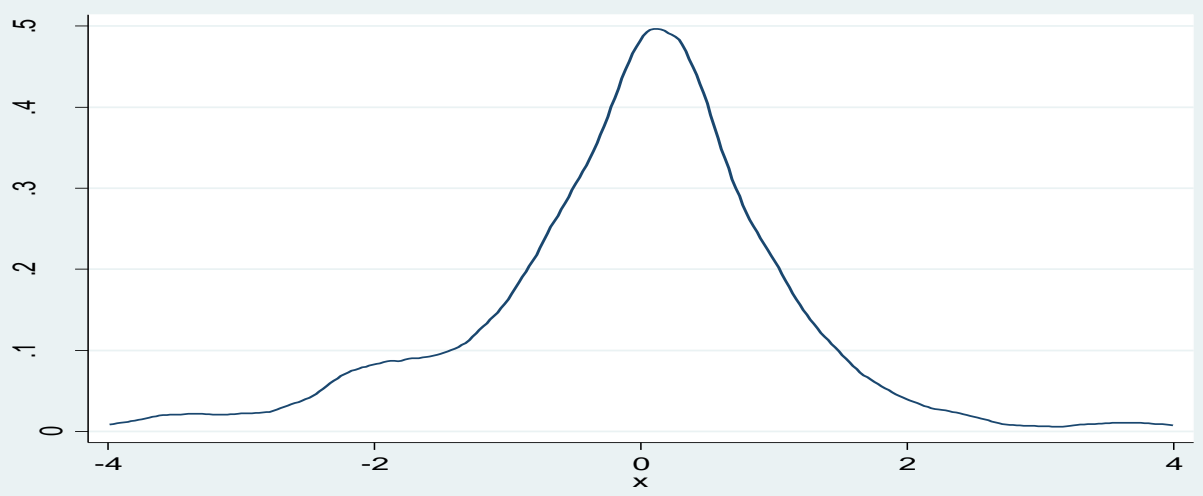

Advanced Economies

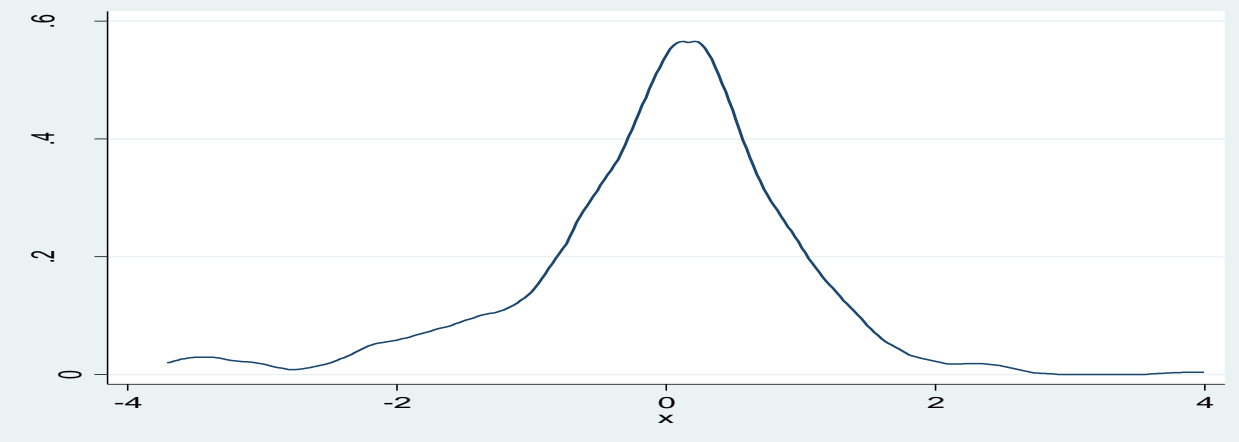

Emerging Market Economies

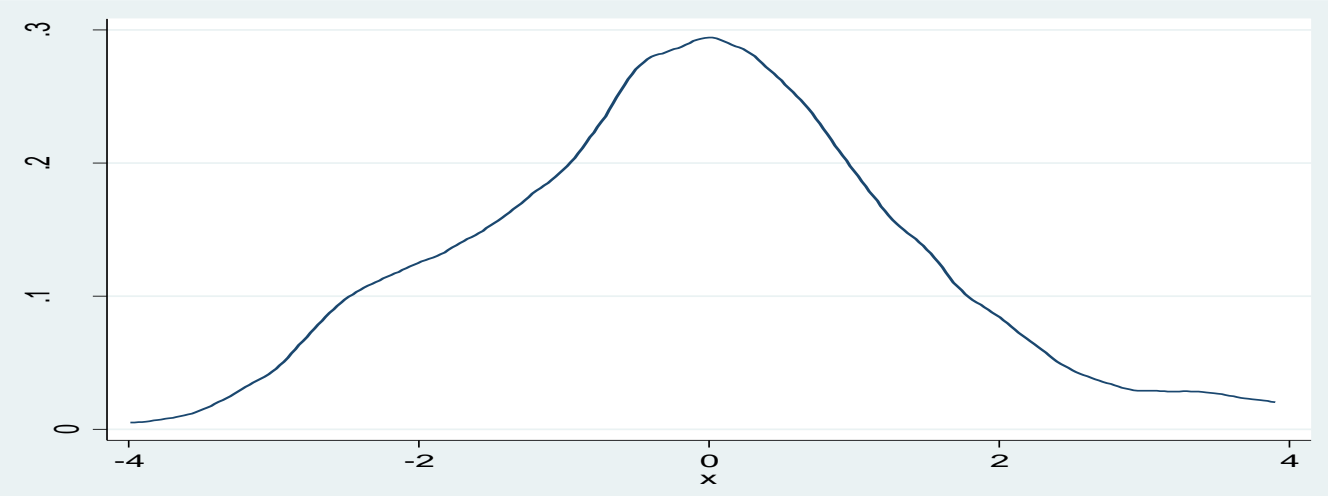

